
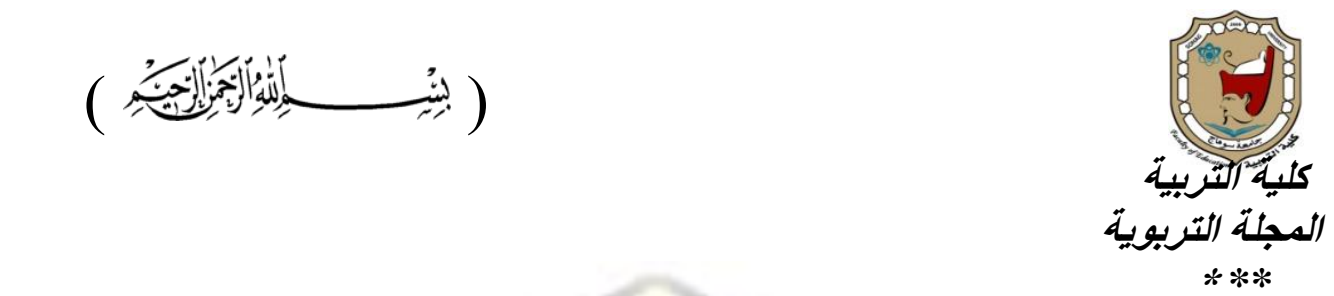

بحث مستل من رسالة دكتوراه بعنوان:

( درجة ممارسة القيادة التشاركية وعلاقتها بـالمناخ المنظمي في الأقسام الاكاد يمية بالجحامعات السعودية )

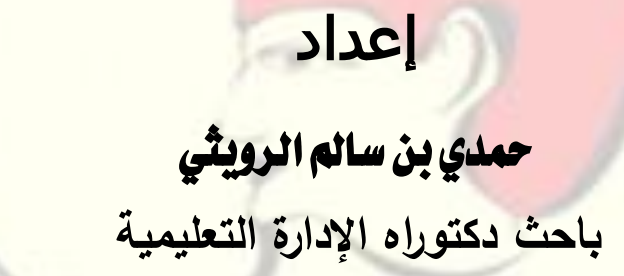

وزارة التعليم - المملكة العربية السعودية

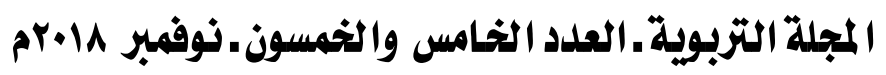

Print:(ISSN 1687-2649) Online:(ISSN 2536-9091) 
هدف البحث إلى التعرف على درجة ممارسة القيادة التشاركية لاى رؤساء الأقسام الأكاديمية في الجامعات السعودية، والكثف عن الفروق بين استجابات أفراد عينة البحث حول درجة ممارسة القيادة التثاركية تبعاً لمتفير: الارجة الكلية، والتعرف على معوقات ممارسة القيادة التثاركية في الجامعات السعودية. وأجري البحث في كل من جامعة: طيبة، والملك سعود، وتبوك، وتكونت عينة البحث

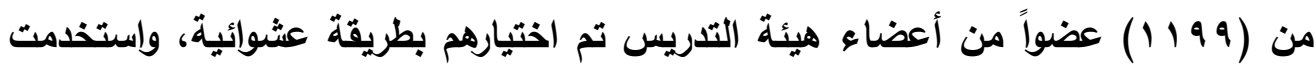
الاستبانة التي تكونت من (اء) عبارة وتضمنت مجالات: المشاركة في صناعة القرار، العلاقات الإنسانية، تفويض السلطة، الاتصال ويناء المعلومات، ومعوقات ممارسة القيادة التثاركية. وتم تحليل البيانات إحصائياً باستخدام برنامج الحزم الإحصائية للعلوم الاجتماعية (SPSS)، وتوصلت نتائج البحث إلى: 1 - أن درجة ممارسة القيادة التثاركية بشكل عام في الجامعات السعودية من وجهة نظر إدان أفراد عينة البحث كاتت بدرجة عالية. ץ - توجد فروق ذات دلالة إحصائية عند مستوى (0,05) بين آراء أفراد عينة البحث حول الدرجة الكلية لممارسة القيادة التشاركية ومجالاتها تبعاً لمتغير الكلية. ويناءً على نتائج البحث تم تقديم عدد من التوصيات والمقترحات.

الكلمات المفتاحية: القيادة التشاركية ، الجامعات السعودية. 
المقدمة

يؤدي التعليم الجامعي دوراً مهماً في بناء المجتمع وخدمته، فهو يتأثر ويؤثر بما يجري من

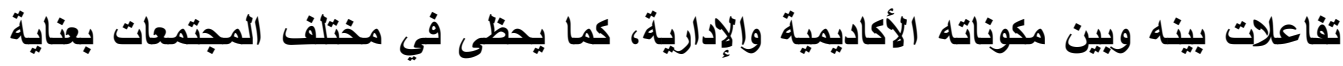

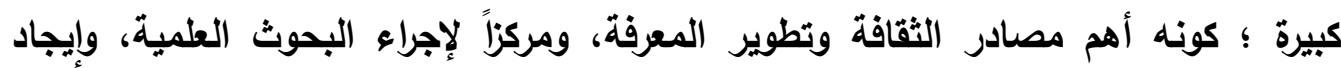

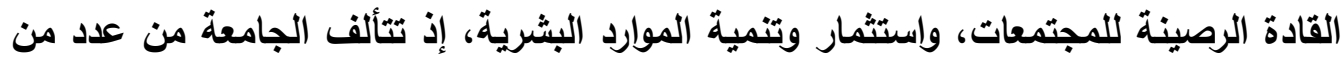

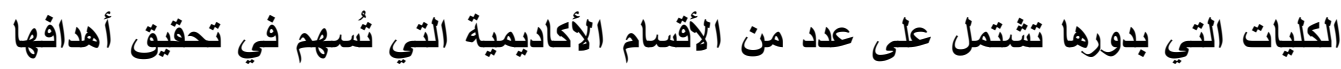
ورسم ملامحها. وتُعد القيادة المحور الرئيس الذي ترتكز عليه كافة الأنثطة المعتمدة في المنظمة، وفي ظل تنامي حجم المنظمات وتثبب أعمالها وتعقدها، أصبحت هنالك حاجة ماسة لإحداث التغيير والتطوير الملائم الذي يضمن لها البقاء والاستمرارية والتميز، ولا تتحقق هذه المهاتهمة إلا في وجود قيادة واعية ذات مهارات قيادية تمكنها من تحريك الجهود وتوجيه الطاقات. فالقيادة هي حلقة الوصل بين العاملين بمختلف مستوياتهم الإدارية، وبين خطط المنظمة

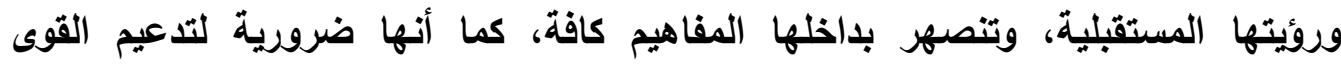
الإيجابية في المنظمة، وتقليص الجوانب السلبية. (سويدان؛ العدواني، ج . . Y).

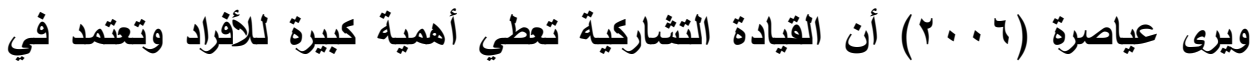
قيادتها على التأثير والاقتناع الثخصي بعيداً عن التهايد والتخويف، فهي تحرص على أنى أخذان آراء الأفراد وتعطيه أهميتهم في العمل، وهي قيادة تعتمد على احترام شخصيتهم، وتعطيهم

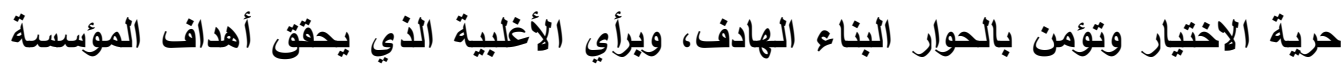

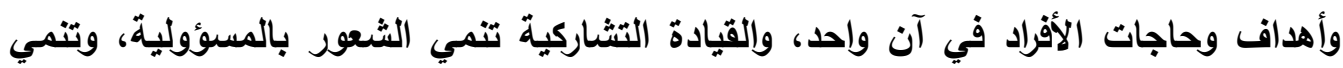

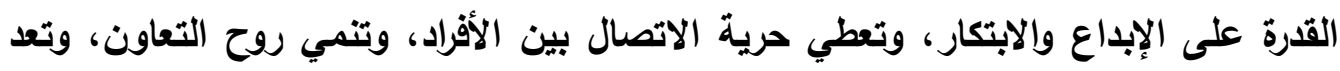

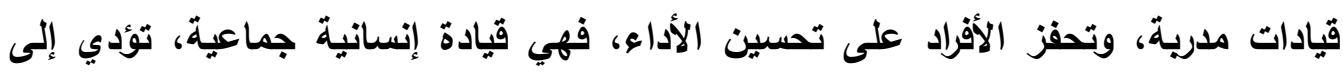

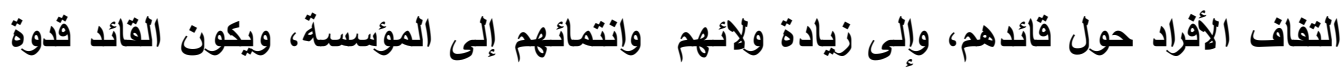
لهم في تصرفاته وممارساته.

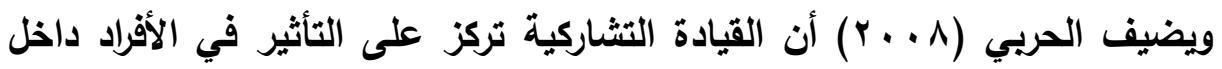
المنظمة في تقدير أمور العمل والأمور التي تهمهم وتمس مصالحهم بما يحقق لديهم الثعور بالمسؤولية ويحفزهم على إجادة العمل والتعاون والانسجام وهذا يجعل مهمة القائد التشاركي 
أكثر سهولة وفاعلية في نفس الوقت، وهي تقوم على العلاقة بين القائد والأفراد في المشاركة في العمليات كصناعة القرارات، والاتصال الإداري، وتقويم الأداء، والتقويض، والتحفيز؛ للوصول إلى تحقيق الأهداف المرجوة.

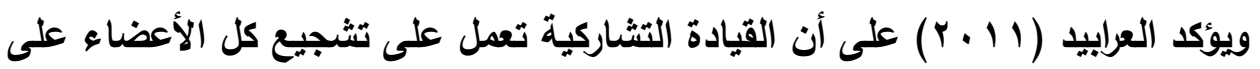
المشاركة الفاعلة في كل مهام المجموعة بتزويدهم بالمعلومات، وتفويضهم للمهام ويإشراكهم

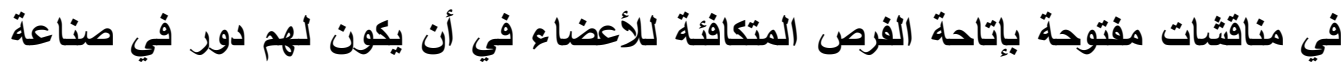
القرارات وتحمل المسؤوليات وتتمية مهاراتهم القيادية. كما بدأ الاهتمام المتزايد بالقيادة التشاركية على المستوى العالمي والعربي والمحلي، فعلى المستوى العالمي اهتمت دراسة هوانج وآخرون(HUANG et at 2010) بدراسة القيادة التشاركية ودورها في تحسين الأداء عن طريق التحفيز أو التعاون، أما على المستوى

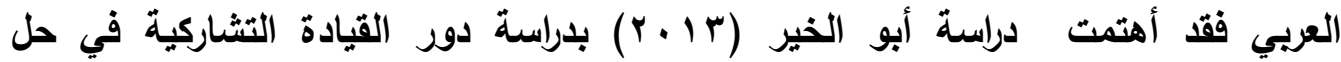
المشكلات في المنظمة، وعلى المستوى المحلي اهتمت دراسة المحمادي (هب إ ا) بدراسة دور القيادة التشاركية في رفع الروح المعنوية للأفراد . وانطلاقاً من أهمية ممارسة القيادة التشاركية في الأقسام الأكاديمية؛ لنجاح الأقسام في القيام بدورها وتحقيق أهدفها؛ فإن البحث الحالي تتجه للكثف عن درجة ممارسة القيادة التشاركية وعلاقتها بالمناخ المنظمي في الاقسام الأكاديمية بالجامعات السعودية.

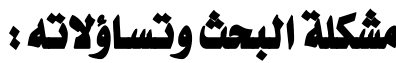

تعد القيادة التشاركية من أهم الأساليب القيادية القادرة على إحداث التغيير في الجامعات، في حين تعتمد العديد من الأقسام الأكاديمية على الأنماط التقليدية من الإدارة التي لا ترتكز على التى إعطاء المساحة الكافية للأعضاء من المشاركة في صناعة القرارات، ومراعاة الجوانب الإنسانية لايهم، وتثجيعهم على الإبداع والابتكار، ويضعف انتاجيتهم مما ق يفقدهم الشعور بالمسؤولية على الرغم أنهم جزع من الجامعة.

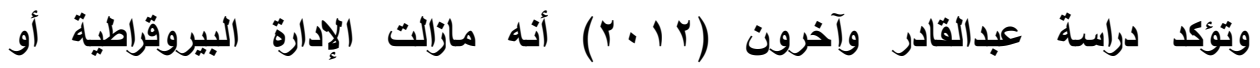
الأوتوقراطية سائدة في الإدارة التعليمية سواء التعليم العالي او العام، فمركزية صناعة القرارات، والخلط بين مفاهيم الولاء الشخصي والمؤسسي لازالت موجودة، والتمسك بالسلطة وعدم الوضوح في التعليمات تعيق تحقيق الأهداف المراد تحقيقها. وتضيف حنان (؟ . . ب) 
أن النمط القيادي التقليدي في الجامعات لم يعد قاد على مواكبة التفيرات المعاصرة، وإيجاد بيئة عمل مناسبة؛ مما يقلل من كفاءة العمل الإداري فيها. وتعد القيادة التشاركية نمطاً فعالاً في التقليل من المشكلات التي تواجهه الأقسام

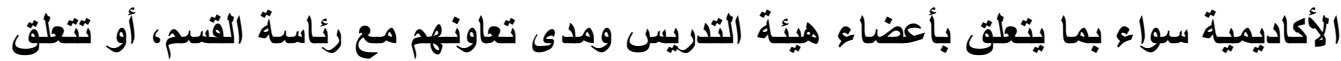
بالشؤون الإدارية الخاصة بالجامعة أو الطلبة، من خلال المشاركة في صناعية القرارات

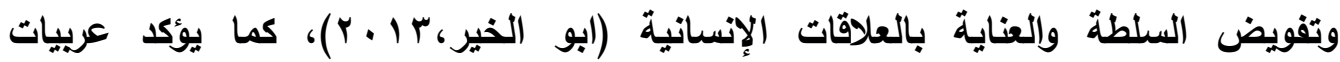

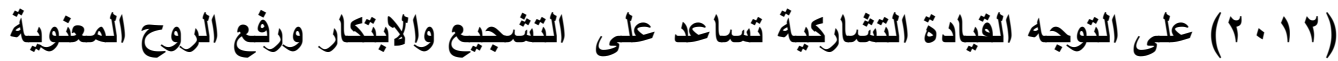
لأعضاء هيئة التدريس في الأقشام الجامعية. فيما أثارت العديد من الدراسات على ضرورة ممارسة القيادة التشاركية في

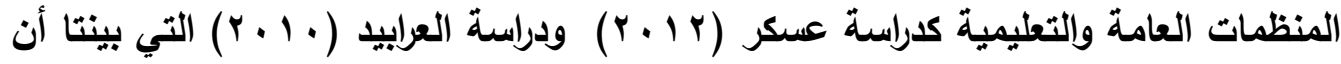
لها دور بالغ في سير العمل وحل المشكلات، وأكلات دراسة ويبي (Wippy,2001) على أنها تزيد من الرضا الوظيفي للعاملين، فيما أظهرت دراسة المحمادي (هبع آ) أنها قادرة

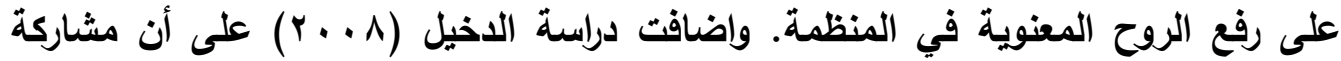
عضو هيئة التدريس في القرار يزيل من فاعليته وتتفيذه.

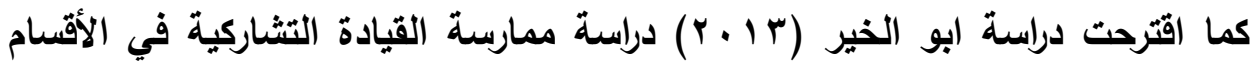
الأكاديمية في الجامعات لبيان أثرها عليه كونها قـ تسهم في تهيئة البيئة الجاذبة للعمل والانتاج. ودراسة أدنيك (Adenik,2011) التي اقترحت بدراسة تأثير المشاركة في القرار

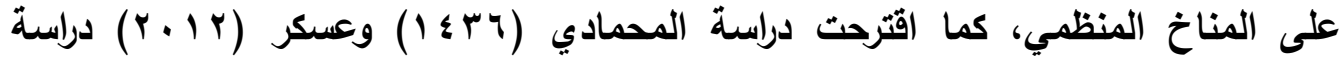
القيادة التشاركية ومعوقاتها على مستوى الجامعات. ويالإضافة إلى ما سبق فقد أجرى الباحث مقابلات مع بعض رؤساء أقسام وأعضاء

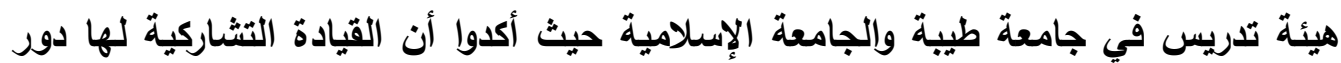
فعال في تقدم القسم وتطوره ولكن هناللك معوقات تحول دون ممارستها بشكل فعال راجعة لكثرة الأعباء عليهم التدريسية والمهام الإدارية بالإضافة إلى انشغال بعض أعضاء هيئة

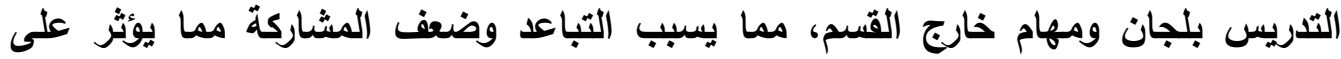
المناخ العام للقسم، في حين اعرب بعض أعضاء هيئة التدريس عن قلة المشاركة في 
صناعة القرار، وضعف الاتصال داخل الأقسام، وعدم رضاهم حول الممارسات الإدارية داخلها، ومن هذا المنطلق فإن مشكلة البحث تكمن في التساؤل الرئيس التالي:

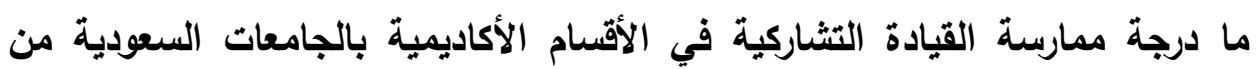

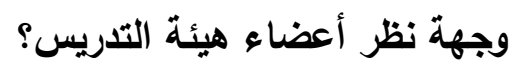
ويتفرع منه التساؤلات الفرعية التالية: التساؤل الأول: ما درجة ممارسة القيادة التشاركية في الأقسام الأكاديمية بالجامعات السعودية؟ التساؤل الثاني: ما المعوقات التي تواجه ممارسة القيادة التشاركية في الأقسام الأكاديمية بالجامعات السعودية؛

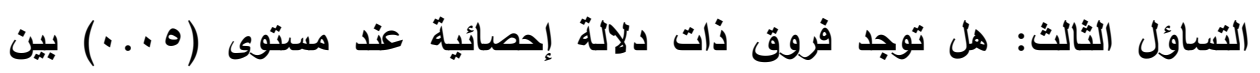
استجابات أفراد عينة البحث حول درجة ممارسة القيادة التثاركية في الأقسام الأكاديمية

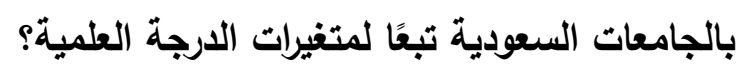
أهداض البحتش؛ سعى البحث الحالي إلى تحقق الاهداف التالية: 1-التعرف على درجة ممارسة القيادة التشاركية في الأقسام الأكاديمية. r-التعرف على المعوقات التي قد تواجه ممارسة القيادة التشاركية في الأقسام الأكاديمية. r-الكشف عن الفروق ذات الدلالة الإحصائية عند مستوى (ه . .) بين استجابات أفراد عينة البحث حول درجة ممارسة القيادة التشاركية في الأقسام الأكاديمية تبعًا لمتفير الكلية.

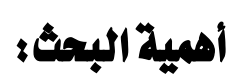

يكتسب البحث أهميتها من خلال ما يلي: ا-تتبع أهمية البحث من أهمية الموضوع الذي يتثاول القيادة التثاركية للأقسام الأكاديمية في الجامعات السعودية. r - قد يُسهم البحث الحالي في إمداد الباحثين والمتخصصين بأدبيات ممارسة القيادة التشاركية في الجامعات السعودية. 
r-إطلاع قيادات الجامعات ورؤساء الأقسام الأكاديمية على المعوقات التي قـ تواجه ممارسة القيادة التشاركية في الأقسام الأكاديمية بالجامعات السعودية. ع -قد يثري البحث الحالي المكتبة العربية بمادة علمية عن القيادة التشاركية.

\section{حلدود البهجث:}

يقتصر البحث في حدوده الموضوعية على درجة ممارسة القيادة التشاركية ومعوقتها في الجامعات السعودية من خلال المجالات التالية: المشاركة في صناعة القرار، العلاقات الإنسانية، تفويض السلطة، الاتصال ويناء المعلومات، أما حدودها البشرية، والمكانية فتقتصر على عينة من أعضاء هيئة التدريس في الجامعات السعودية التالية: جامعة طيبة بالمدينة المنورة، وجامعة الملك سعود بالرياض وجامعة تبوك، أما حدودها الزمنية أُجري

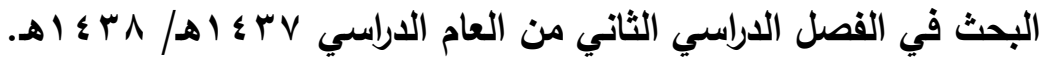

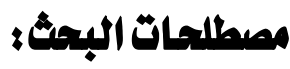

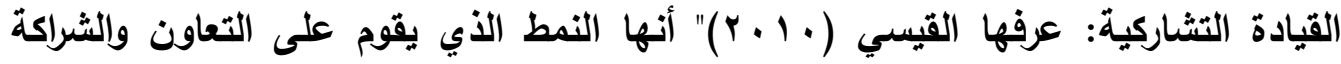

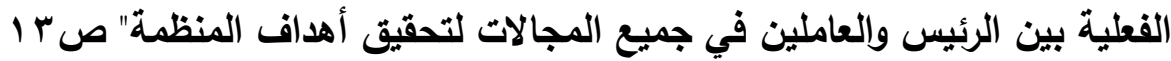
وتعرف إجرائياً: بأنها تفاعل رئيس القسم مع اعضاء هيئة التدريس في المواقف الجماعية من المشاركة في صناعة القزار، والعلاقات الإنسانية، وتفويض السلطة، والاتصال ويناء المعلومات لتحقيق الأهداف المرغوية.

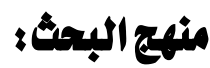
استخدم البحث الحالي المنهج الوصفي التحليلي، الذي يعتمد على دراسة الواقع ويهتم بوصفه وصفاً دقيقاً، ويعبر عنه تعبيراً كيفياً بوصف الظاهرة وتوضيح خصائصها، أو تعبيراً

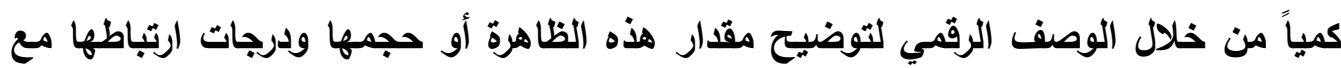

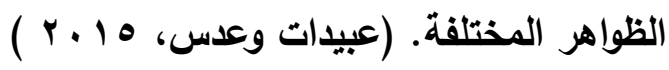

\section{مجتمع البحث والمينة:}

تكون مجتمع البحث من جميع أعضاء هيئة التدريس في (جامعة طيبة، وجامعة الملك

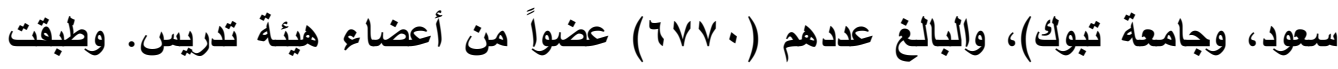
الاراسة على عينة مقدارها (9 V I I ) عضوًا من خلال الطريقة الطبقية العشوائية. 


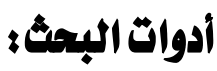

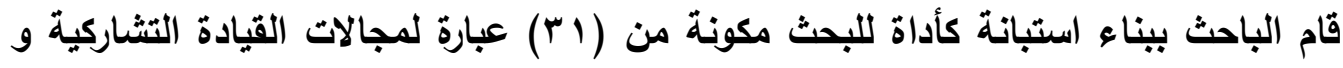

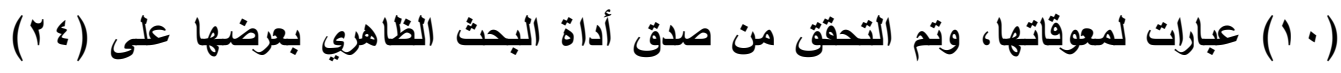

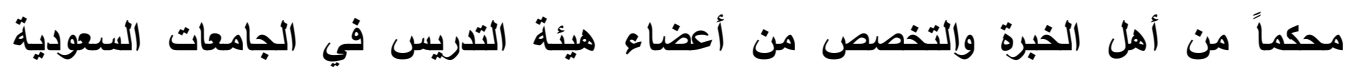

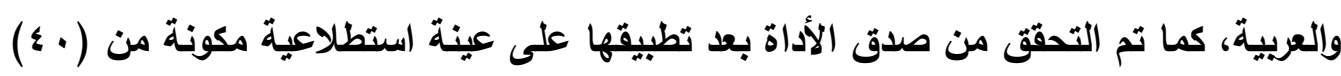

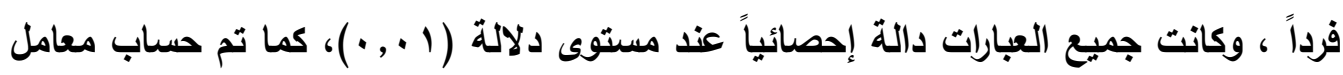

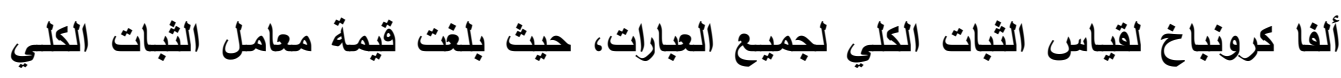

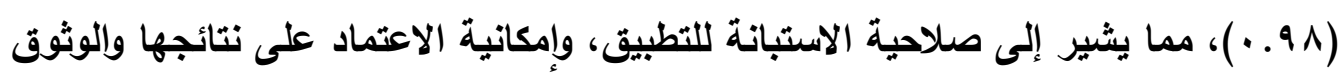

الإطار النظري

القيادةالتشاركية

التثاركية لغةً: شرك/ الثرُكةُ والثرِكة، سواء مخالطة الثريكين، ويقال اشتركنا بمعنى

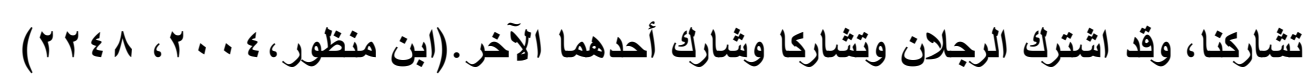
وتعددت واختلفت تعريفات الباحثين في موضوع القيادة التشاركية والمفكرين في

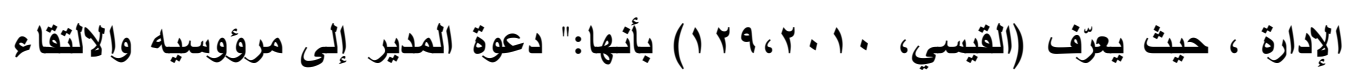

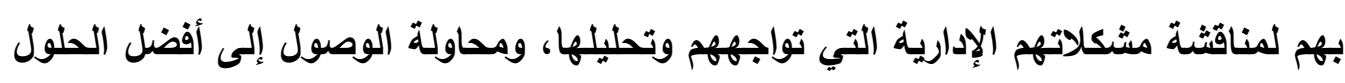

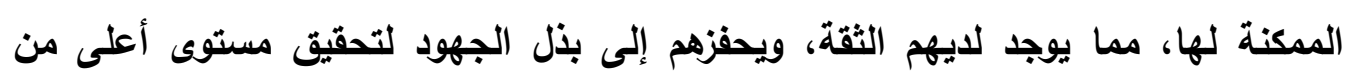

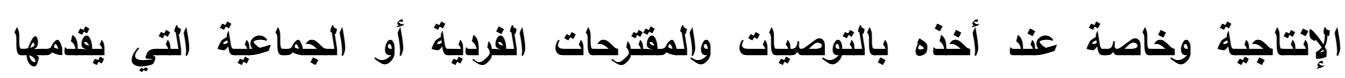
المرؤوسين التي بدورها تيسر له تحديد الأهداف واتخاذ القزارات.

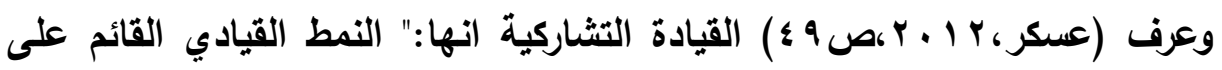

المشورة والتعاون والثراكة الفعلية بين المدير والعاملين في مجال التغيير والتخطيط والتوجيه والتتسيق والرقابة في العمل واتخاذ القرارات وحل المشكلات بما يكفل تحقيق أهداف المنظمة". 


\section{درجة ممارسة القيادة التشاركية وعلاقتها بالمناخ المنظمي في الأقسام الأكاديمية بالجامعات السعودية.}

ويعرفها (Kocolowski,2010,p24) بأنها: "العملية الجماعية التي يشترك فيها

العاملون مع الإدارة في اتخاذ القرارات المرتبطة بالعمل والتي تسهم في رفع الروح المعنوية

للعاملين"

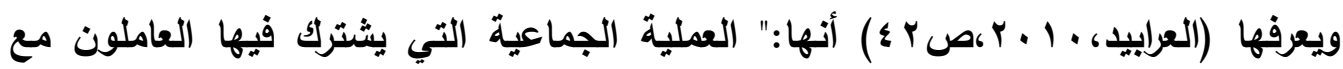
الإدارة في اتخاذ القرارات المرتبطة بالعمل والتي تسهم في رفع الروح المعنوية للعاملين".

ونلاحظ ان القيادة التشاركية تشتمل على الاتي: تُشهم القيادة التشاركية في تطوير

وتنمية مهارات العاملين القيادية، ورفع روحهم المعنوية والثعور بالتقدير واحترام الذات. العمليات الإدارية تتم من خلال القيادة التشاركية بشكل جماعي؛ حيث تتيح الفرص لجميع العاملين بالمشاركة فيها. تحقق القيادة التثاركية مستوى مرتفع من الثقة المتبادلة بين المدير والعاملين مما يحقق دافعية عالية للعمل. تحافظ القيادة التشاركية على التركيز على أهداف المنظمة والعمل تحقيقها بكفاءة عالية كونها أهداف مشتركة.

\section{أهداض القيادةالتشماركية:}

تقدم القيادة التشاركية مفهوم الممارسة القيادية كظاهرة على مستوى الفريق؛ حيث تتم سلوكياتها المتعددة من قبل الأفراد وليس فقط من قبل أولئك الذين في الأعلى أو من قبل الذين في القيادة الرسمية، وهي بذلك العملية القيادية التعاونية أو الظاهرة التي تعتمد على الفرق أو الجماعات والتي تؤثثر في بعضها البعض مع تبادل جماعي للواجبات والمسؤوليات.

(Kocolowski,2010)

ويهدف تطبيق القيادة التشاركية إلى إيجاد بيئة إدارية مختلفة تواكب التطورات الحاصلة في عالم القيادة الإدارية، وكذلك فهي تسعى إلى الحصول على كفاءة وإنتاجية عالية من جميع المرؤوسين بما يجدونه من دعم وثثة من القائد التشاركي من خلال سعيها

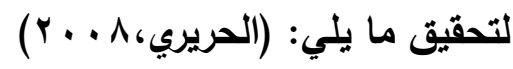


-التأكيا على الأكاء في التعامل مع المستجدات واللجوء إلى التحليل المنطقي في حل المشكلات.

-مراعاة السيطرة الأتية من خلال فهم الآخرين للأهداف.

-قيادة المرؤوسين نحو الاستفادة من كل تقدير مجهوداتهم وشحذ هممهم وتفجير طاقاتهم. -مواجهة النزعات وحلها بالطرق الحديثة لمجابهتها وعدم إهمالها أو التحذير منها. -التأكيا على أن يتم الاتصال في القيادة التشاركية بشكل ثنائي وتبادلي بين القائد ومروؤوسيه.

-ضرورة اتخاذ القرارات بالطرق السليمة مع إثراك المرؤوسين للوصول إلى قرار مثالي يسعى الجميع في تطبيقه. - إثراك المرؤوسين في الخطط الاستراتيجية للمنظمات.

\section{أهمية الثيادةالتشماركيةدا}

تعمل القيادة التشاركية على شحذ الهمم وتقوية الشعور بالمسؤولية لاى العاملين في الطبقات الانيا من المنظمات ويجعهم يقبلون على العمل في مسؤولة وروح إيجابية وفي النهاية تكون المسؤولية جماعية مما يقلل العبء على الإدارة العليا، كما أن اختلاف وجهات النظر والذي ينتج عن القيادة التشاركية يمكن أن يستغل لصالح العمل وتطويره وتقدمه، وأن قدرة وفعالية صغار الموظفين والعمال لها قوة الدفع في القيادة التشاركية وعلى القياديين الأخذ بآراء الموظفين وخاصة الناجح منها. (أحمد، و 9 V )

كما يؤكد المؤيدين للقيادة التشاركية أن عمليات صنع القرار الجماعي لابد أن تكون مركزاً لاهتمام القادة؛ كونها تعزز الفاعلية التنظيمية والتي تتطلب بالضرورة قيادة تثاركية، 
كما أن السلطة والتأثير في القيادة التشاركية مفتوحان لأي مستفيل من المنظمة استناداً إلى فئل خبرته وحقه المشروع في الاختيار وإلى دوره المهم في تنفيذ القرارات، ويتوقف على القيادة التشاركية وقيادة الفريق منح مزيد من السلطات للهيئات المحلية، ومزيد من الممارسات الديمقراطية للعاملين، ومزيد من المساعلة للقادة المحليين من قبل الإدارة المركزية والمجتمع المحلى، كما أن مشاركة المرؤوسين في صناعة القرارات تقلل من الصراعات داخل المنظمة، وتزيد من الروح المعنوية للعاملين، وتقلل من حالات الغياب عن العمل، وأنها تقوم على فريق أو مجموعة أو مجتمع بدلاً من الفرد، ولها دور في الاعتماد المتبادل والترابط والتلاحم داخل المنظمة، تهيئ القيادة التشاركية فرصة للتمكين بدلاً من السيطرة وتملك القرار في المنظمة.

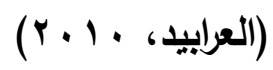

ويرى الباحث أن أهمية القيادة التشاركية تمكن في كون المنظمة تعمل كفريق من حيث المشاركة في صنعة القرار والتخطيط لتحقيق الأهداف المشتركة وإلترابط داخل المنظمة كما تفتح فرص للتمكين بدلاً من التسلط والسيطرة، وتقوي العلاقات الإنسانية بين العاملين والقيادة وتثمعرهم بانتمائهم للمنظمة ورفع روحهم المعنوية.

\section{مبرات استخدام القيادة التشئاركية في الإدارة التمايمية والجامعية:}

لقد ثبث ان المؤسسات والمنضمات المعاصرة تكون أكثر فاعلية في تعزيز أداء العمل وارتفاع الترابط التظيمي متى ما كانت بيئاتها أكثر تثاركية وتعاونية وتمكن الآخرين من المشاركة في عملية صنع القرارات وحل المشكلات وذلك لأسباب تواجهها هذه المنظمات المعاصرة منها: العولمة، بالإضافة كون المجتمعات أصبحت أثر تنوعاً، والتفير التقني والتكنولوجي السريع، وقلة الموارد. (Kim,2011)

ويشير (Sara \&Chatziioannidis,2013) إلى سببين رئيسين يحتمان على الجامعات التوجه للقيادة التشاركية الأول: ضرورة التمشي مع الاتجاهات الحديثة في الإدارة 
التنظيمية للجامعات بالتغيير والتظوير للتوجه نحو منظمات التعلم والتنافسية، وهذا لا يتحقق إلا في مجتمعات تثاركية، والثاني: زيادة الضغوط الاجتماعية والرغبة في المساعلة والاصلاحات التعليمية التي تؤدي إلى زيادة فعالية الجامعات بالاستعانة بمشاركة كافة كوادرها لتحملهم المسؤولية وزيادة الالتزام لايهم.

ويري الباحث استفاد المجال التربوي والتعليمي من المجالات الأخرى كالتجاري والصناعي والعسكري الذي سبقته في التوصل إلى نماذج متطورة في قيادة العمل، ومما لا شك فيه فإن توظيف ما توصلت له تلك المجالات في المجال التريوي سيكون له مردوده على القيادة التعليمية والتربوية بما يتناسب مع الموارد والمعطيات الخاصة به.

\section{مجالات القيادةالتشماركية}

\section{ا}

ويقصد به اشتراك أعضاء هيئة التدريس في القسم مع رؤساء الأقسام وتعاونهم معاً في صناعة القرارات ضماناً لوضوح الرويا وتبادل الآراء بينهم، كما أن اللجوء إلى تبادل الرأي مع من يهمهم القرار؛ من أجل ضمان تعاونهم اختيارياً والتزامهم بالتنفيذ، الأمر الذي يسهل عمل رؤساء الأقسام، ومن فوائده: المشارك في صناعة القرار أكثر الناس تحمساً لتفيذه مما يسهل على القيادة أعمالها. وإتاحة المجال للمرؤوسين للتعبير عن آرائهم، والاسهام بمقترحاتهم في كل ما يهم أعمالهم أو نشاطاتهم، ولذلك أثر في فهم العمل وإنجازه، وإدراك حاجته للتحسين والتطوير، والإلمام بالدور المنوط بكل واحد منهم، وتحسين العلاقة بين العاملين، ورفع روحهم المعنوية. وإتاحة الفرصة للمرؤوسين لاستخدام مواهبهم وإنطلاق طاقاتهم الكامنة، والاستفادة من قدراتهم في المجالات التي يتقتونها. (القيسي، • 1 r) 


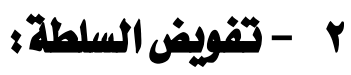

ويقصد بتفويض السلطة كما يرها الصيرفي (ץ . . ץ) عملية السماح الاختياري بنقل جزء من السلطة من الرئيس إلى المرؤوس، وعندما يقبل الأخير هذا التفويض فإنه يلتزم بأداء الواجبات التي يكلفه بها رئيسه ويمارس الصلاحيات اللازمة لأدائها ويصبح مسؤولاًا

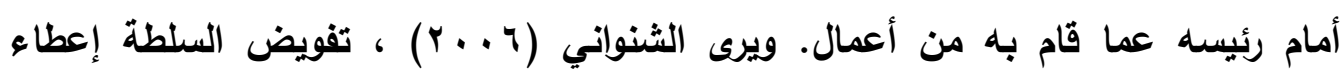

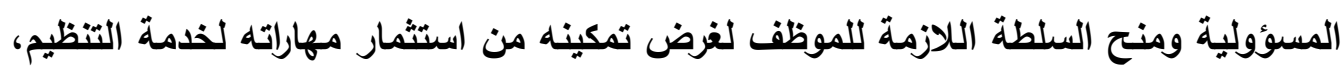
وتتمكن المنظمة من تحقيق أهدافها وممارسه نثاطاتها.

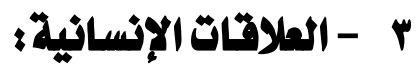

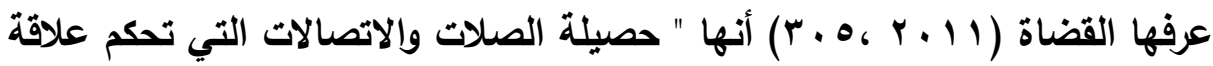
الفرد بغيره من الناس، والمؤسسات التي يتعامل معها، وفق قوانين المجتمع ومعاييره الاجتماعية، وذلك من خلال مؤسسات المجتمع المختلفة كالأسرة وجماعات العمل وجماعات الرفاق والأقارب ومؤسسات المجتمع المختلفة".

وتتجلى أهمية العلاقات الإنسانية في المساهمة في نجاح المؤسسة وتحقيق حاجات العاملين، وتحسين العلاقة بين الرئيس والمرؤوسين، وتطوير عملية الاتصال

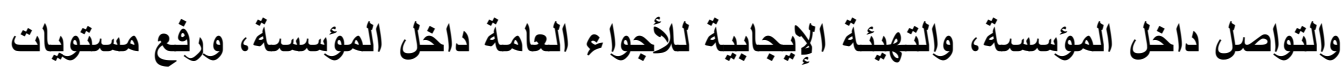
الإنتاج نتيجة لتطبيق أنظمة المكافآت والحوافز التي تؤدي دوراً رئساً في تحفيز العاملين وشعورهم بالرضا، وتعزيز الانتماء إلى العمل من قبل الجميع. (الحريري، ، 1 + ب) 
ع - الاتصال وبناء المطلومات؛

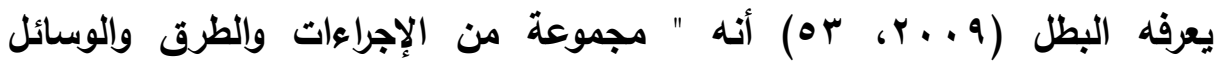
والترتيبات، والتي تكفل إنتاج وتوصيل واستخدام البيانات اللازم توافرها لاتخاذ قرارات سليمة

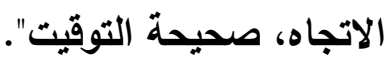

تتكون عملية الاتصال الإداري من عدة عناصر متكاملة لا يمكن أن نفصل بينها كون أي

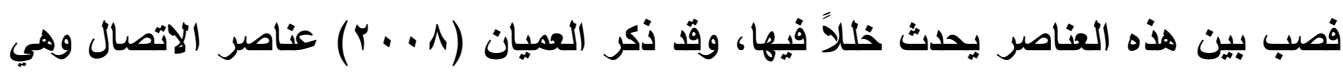
كما يلي: - n

1-المصدر: وهو الثخص أو الجهة التي تصدر منها الرسالة. r- ب-الرسالة: مضمون الاتصال، أو موضوعه. ب-الوسيلة: الطريقة التي يتم بها الاتصال، أو قناة الاتصال ؛ -المستقبل: الثخص، أو الجهة التي تستقبل الرسالة. ه-النتيجة (الاستجابة أو الأثر): مدى تحقق الأهداف التي من أجلها تم الاتصال.

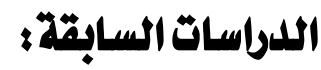
أوثًا ا الدراسات العربية:

واجه الباحث ندرة في الاراسات التي تناولت القيادة التثاركية في التعليم العالي سوى

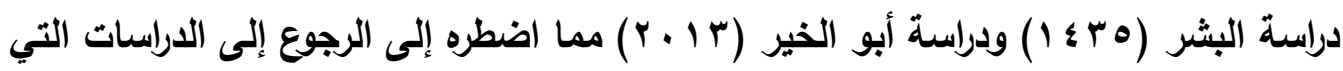

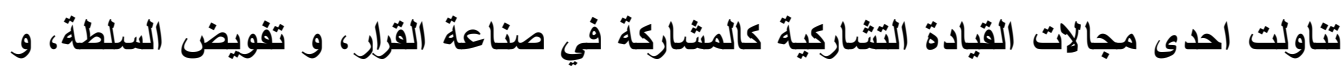
العلاقات الانسانية، والاتصال ويناء المعلومات. 


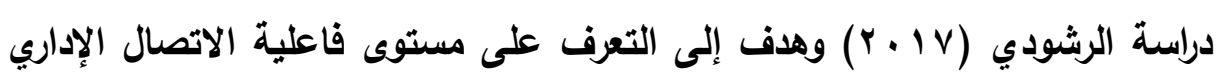

في جامعة القصيم ودوره في تحسين الاداء المؤسسي، وتكونت عينة الدراسة من (9 . 1) قائداً أكاديمياً وإدارياً، وإتخدمت المنهج الوصفي المسحي، ولتحقيق هدف الدراسة تم تصميم استبانة تكونت جزاين الأول لقياس فاعلية الاتصال الإداري ويتكون من المجالات التالية: عملية الاتصال، وسائل الاتصال، الاتصال مع إدارة الجامعة، الاتصال مع العاملين، والجزء الثاني لقياس مستوى تحسن الأداء المؤسسي ويتكون من أريعة مجالات هي: بيئة وأساليب العمل، الفاعلية وإلكفاعة المؤسسية، إدارة الموارد المتاحة، الأداء الإداري، وتوصلت الدراسة إلى أن متوسط الاتصال الإداري جاء بلرجة متوسطة، وأن مستوى تحسن الأداء جاء بارجة عالية، وأن هنالك علاقة إيجابية بين مستوى فاعلية الاتصال الإداري ومستوى تحسن الأداء المؤسسي.

دراسة البشر (هب \& 1) وهدفت إلى معرفة متطلبات القيادة التشاركية لاى رؤساء الأقسام الأكاديمية بكلية العلوم الاجتماعية في جامعة الامام محمد بن سعود الإسلامية، وطبقت الاراسة على عينة عثوائية مقدارها (هو (1) من أعضاء هيئة التدريس، ولتحقيق أهداف الدراسة استخدمت الدراسة المنهج الوصفي المسحي، وتم تصميم استبانة تحتوي على جزئيين الاول متطلبات القيادة التثاركية وإثثاني معوقات القيادة التثاركية لاى رؤساء الأقتسام العلمية في جامعة الامام محمد بن سعود الإسلامية، وتوصلت الدراسة إلى نتائج أبرزها: أن أفراد عينة الدراسة موافقون بدرجة كبيرة على عبارات متطلبات القيادة التثاركية لاى الأقسام العلمية في جامعة الامام محمد بن سعود الإسلامية، حيث كانت العبارات المتعلقة بالعلاقات الانسانية أكثر العبارات من حيث المتوسط، وأن أفراد عينة الدراسة موافقون بلرجة كبيرة على عبارات معوقات متطلبات القيادة التثاركية لاى الأفسام العلمية في جامعة الامام محمد بن سعود الإسلامية. 


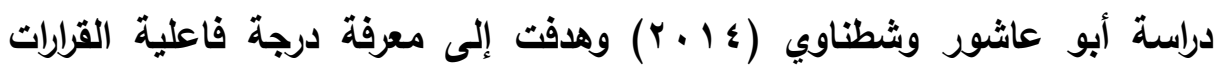

المتخذة في مجالس الأقسام الأكاديمية في الجامعات الأردنية، وطبقت الدراسة على عينة مقراها (rV^) من أعضاء هيئة التدريس ولتحقيق أهداف الدراسة استخدمت الدراسة المنهج الوصفي المسحي وتم تصميم استبانة تحتوي على أربعة مجالات (المشاركة في اتخاذ القرارات، الثقافة المنظمية، التمكين، القيادة) ، وتوصلت الدراسة إلى نتائج أهمها: ان درجة فاعلية القرارات المتخذة في مجالس الأقسام الأكاديمية في الجامعات الأردنية من وجهة نظر أعضاء هيئة التدريس كانت مرتفعة. وأن هنالك علاقة عند المقارنة بين الجامعات الحكومية والخاصة لصالح الجامعات الحكومية في فاعلية اتخاذ القرارات، كما أن هنالك دلالة تعزى لمتغير الجامعة لصالح جامعة اليرموك في المشاركة في اتخاذ القرارات.

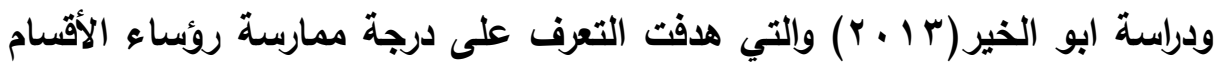
في الجامعات الأردنية الخاصة في عمان للقيادة التشاركية وعلاقتها بحل المشكلات، وتكونت

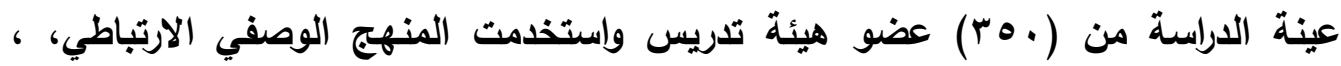
واستخدمت استبانتان الأولى لقياس درجة ممارسة القيادة التشاركية وشملت المشاركة في اتخاذ القرار والعلاقات الانسانية والتحفيز، أما الثانية لقياس مقرة رؤساء الأقسام على حل المشكلات، وتوصلت إلى أن درجة ممارسة رؤساء الأقسام في الجامعات الأردنية الخاصة في عمان للقيادة التشاركية جاعت بلرجة متوسطة وكذلك مقدرته على حل المشكلات، وأن هنالك علاقة طردية بين ممارسة القيادة التثاركية لرؤساء الأقسام ومقدرتهم على حل المشكلات.

أما دراسة عربيات (r ا ب r) فهدفت إلى معرفة الأنماط القيادية التربوية السائدة لاى رؤساء الأقسام الأكاديمية في جامعة بقعاء التطبيقية وأثرها على الأداء الوظيفي لأعضاء هيئة التدريس، ، وتكونت عينة الدراسة من (YrY) عضو هيئة تدريس، واستخدمت المنهج الوصفي المسحي، ولتحقيق هدف الدراسة تم تصميم استبانة تكونت من اريعة مجالات لقياس 
الانماط القيادية السائدة (الديمقراطي، التقليدي، التسلطي، الترسلي)، ومجال خامس لقياس مستوى الأداء الوظيفي، وتوصلت الدراسة إلى وجود مستوى مرتفع من الأداء لأعضاء هيئة التذريس إذ أظهرت النتائج أن المتوسط الحسابي الكلي لاستجابة أفراد عينة الدراسة على فقرات الاستبانة المتعلق بالأداء الوظيفي بلغ ا ـ.ـ؛، وتبن وجود أثر لنمط القيادة الديمقراطية على مستوى أداء أعضاء هيئة التدريس وعدم وجود أثر لنمطي القيادة التقليدي والتسلطي

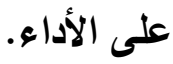

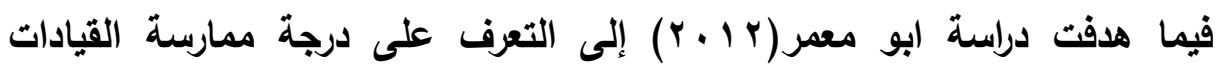
الإدارية في الجامعات القلسطينية بمحافظات غزة لتفويض السلطة من وجهة نظر موظقيهم وسبل تفعيلها، ولتحقيق أهداف استخدمت الدراسة المنهج الوصفي التحليلي، وتم تصميم استبانه لقياس ممارسة القيادة الإدارية للتفويض ومقترحات لتفعيل تفويض السلطة، و تم توزيعها على عينة الاراسة المكونة من(به r) موظف وموظفة في الجامعات القلسطينية بمحافظات غزة للعام، وتوصلت الدراسة إلى نتائج أبرزها: أن درجة ممارسة القيادات الإدارية في الجامعات الفلسطينية بمحافظات غزة لتفويض السلطة من وجهة نظر موظفي هم كانت متوسطة، توجد فروق ذات دلالة إحصائية عند مستوى الدلالة (ه . . ) بين متوسط تقديرات عينة الدراسة لارجة ممارسة القيادات الإدارية في الجامعات القلسطينية بمحافظات غزة لتفويض السلطة تعزى لمتغير المؤهل العلمي.

بينما هدفت دراسة الاشقر و مونس (Y Y • Y) إلى التعرف إلى درجة ممارسة عضو هيئة التدريس للعلاقات الإنسانية من وجهة نظر طلبته بالجامعات الفلسطينية، وقد استخدم الباحثون المنهج الوصفي، واستخدمت الدراسة المنهج الوصفي التحليلي وتكونت عينية

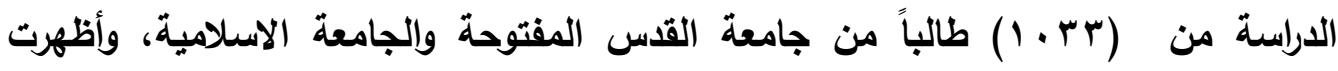
الدراسة نتائج أبرزها أن مستوى ممارسة العلاقات الانسانية جاء بدرجة كبيرة، وكذلك توجد فروق ذات دلالة إحصائية عند مستوى الدلالة (ه...) بين تقديرات متوسطات عينة 
الدراسة لدور ممارسة عضو هيئة التدريس بالجامعات الفلسطينية للعلاقات الإنسانية تعزي لعامل الجنس لصالح الأكور ، ولعامل الكلية لصالح الكليات الإنسانية .

كما اجرى الدخيل (^ . ㄷ) دراسته التي هدفت إلى تعديد درجة مشاركة أعضاء هيئة التدريس في صناعة القرارات الخاصة بشؤون القسم وشؤون أعضاء هيئة التدريس وشؤون الطلاب بكليات المعلمين في السعودية، وشملت الدراسة (ه . ع) من أعضاء هيئة التدريس في سبع كليات اختيرت قصدياً، واستخدمت الاراسة المنهج الوصفي التحليلي، وقد استخدم الدراسة استبانة اشتملت على المجالات التالية: المشاركة في قرارات( القسم، أعضاء هيئة التدريس، الطلاب) و وزعت على سبع كليات، وتوصلت إلى أن عضو هيئة التدريس يشارك بدرجة ضعيفة في القرارات الخاصة بشؤون القسم ويشارك بدرجة ضعيفة في صنع القرارات الخاصة بشؤون أعضاء هيئة التدريس وكذلك بلرجة ضعيفة جاعت مشاركته في صنع القرارات الخاصة بشؤون الطلبة. وان مشاركة عضو هيئة التدريس في القرارات بشكل عام يزيد فاعليتها.

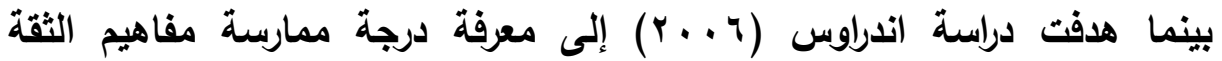
والتفويض لدى القيادات الأكاديمية في الجامعات الأردنية الرسمية، واستخدمت الدراسة المنهج الوصفي التحليلي وتكونت عينية الدراسة من جميع القادة الأكاديميين والبالغ عددهم (^ ^ ؛ )، وأظهرت الدراسة شيوع كل من ممارسات مفاهيم الثقة مثل دقة المعلومات وتوافرها، وشيوع مفاهيم التفويض بمجاليها الأكاديمي بلرجة عالية وكذلك السلوك القيادي الذي كانت درجة ممارسته عالية ككل في مجال السياسة الإدارية والقيم المنظمية السائدة. - الدراسات الأجنبية التي تناولت القيادة التشاركية:

دراسة ميوندي (Muindi,2011) وهدفت الدراسة إلى معرفة العلاقة بين المشاركة في اتخاذ القرار والرضا بين الموظفين الأكاديميين في جامعة نبرويي العامة، وتكون مجتمع 
الدراسة من كافة الأعضاء غير الإداريين للموظفين الأكاديميين في كلية إدارة الأعمال في جامعة نيرويب، وتم استثناء العمداء ورؤساء الأقسام الذين فعلياً هم أعضاء في مجلس إدارة الجامعة، واستخدمت الاراسة المنهج الوصفي المسحي، والاستبانة كأداة للاراسة، وتوصلت الدراسة إلى نتائج أهمها وجود ارتباط بين هام جداً بين الرضا الوظيفي والمشاركة في اتخاذ القرار، و كنلك وجود ارتباط ايجابي قوي بين المشاركة في اتخاذ القرار والرضا الوظيفي فيما يعلق بظرف بيئة العمل العامة، الرواتب، الترقية، استخدام المهارات، تصميم العمل، والتغذية الاسترجاعية للعمل. وأن مستوى الرضا الوظيفي للعاملين في كلية إدارة الأعمال يزداد بمقدار مشاركتهم في اتخاذ القرارات.

بينما هدفت دراسة هواتج وآخرون (HUANG et at 2010) إلى معرفة عما إذا كان سلوك القيادة التشاركية مرتبط بتحسين الأداء في العمل عن طريث عملية تحفيزية أو عملية قائمة على أساس التبادل والتعاون، وكاتت عينة الدراسة (orv ) موظف، واستخدمت الدراسة المنهج الوصفي التحليلي، كما استخدمت نموذجين نظريين وهما النموذج التحفيزي والنموذج التبادلي وعلى نطاق واسع لاكتشاف الآلية النفسية لأثر سلوك القيادة للرؤساء على المرؤوسين، وقد توصلت الدراسة إلى عدد من النتائج منها: أن النموذج التحفيزي للقيادة التشاركية يملك قوة أكثر من النموذج التبادلي في حالة المرؤوسين الإداريين، ومع ذللك فإن النموذج يملك قرة على شرح أكثر من النموذج التحفيزي في حالة المرؤوسين غير الإداريين، كما أن سلوك القيادة التشاركية مرتبط بأداء المهمة وسلوك المواطنة المنظمية وكذلك مرتبطة بالثقة بالمشرف أكثر من التمكين النفسي في حالة عينة المرؤوسين الإداريين، كما أن هنالك تأثير لسياق العمل على القيادة ومختلف الآليات النفسية للقيادة التثاركية والآفاق المحتملة لنظريات القيادة.

وكما أن دراسة ويبي (Wippy,2001) هدفت إلى معرفة النمط القيادي للرؤساء الأكاديميين والرضا الوظيفي لاى أعضاء هيئة التدريس بجامعة قومان ،وكانت عينة الدراسة ، م1 من 
أعضاء هيئة التدريس، وأُستخدم المنهج الوصفي، في حين، واستخدمت الدراسة استبانة بهدف قياس الرضا الوظيفي لدى أعضاء هيئة التدريس. وقا توصلت الدراسة إلى مجموعة من النتائج من أهمها : أن سلطة الرئيس كاتت ضعيفة في حين كاتت ؛ ووجود رضا وظيفي داخلي عال المهام واضحة. ، وأن النمط الديمقرطي يزيد من الرضا الوظيفي لاى أعضاء هيئة التدريس

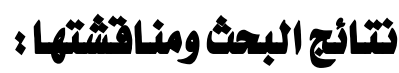

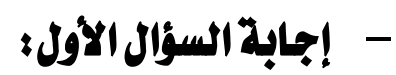

ما درجة ممارسة القيادة التشاركية في الاقسام الأكاديمية بالجامعات السعودية؟

للإجابة على السؤال الأول تم استخدام المتوسط الحسابي والانحراف المعياري والوزن النسبي لارجة ممارسة القيادة التثاركية في الأقسام الأكاديمية في الجامعات السعودية للارجة الإولية الكلية

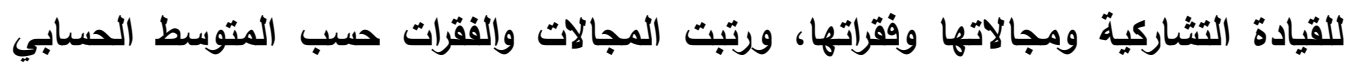

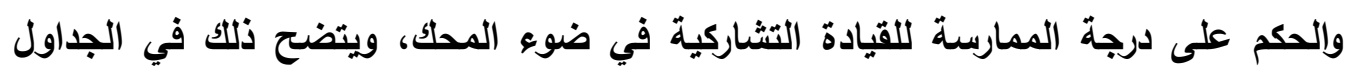

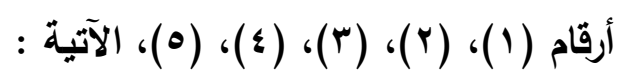

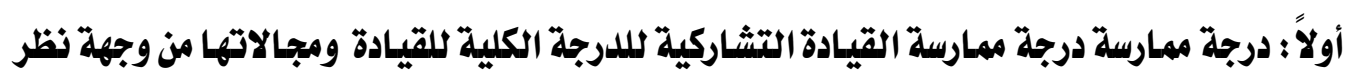

آراء العينة :

جدول ( ) المتوسطات والانحرافات المعيارية لدرجة ممارسة القيادة التشاركية ومجالاتها

\begin{tabular}{|c|c|c|c|c|c|c|}
\hline الترتيب & الممارجة & النسبي & المعياري & الحستوسي & المجالات & \\
\hline 1 & عالية & 0.74 & 0.86 & 3.71 & المشاركة في صناعة القرار & 1 \\
\hline r & عالية & 0.74 & 0.78 & 3.68 & تفويض السلطة & r \\
\hline$r$ & عالية & 0.71 & 0.92 & 3.53 & العلاقات الإنساتية & $r$ \\
\hline$\varepsilon$ & عالية & 0.68 & 0.85 & 3.42 & الاتصال ويناء المعلومـات & $\varepsilon$ \\
\hline \multicolumn{2}{|c|}{ عالية } & 0.72 & 0.78 & 3.59 & \multicolumn{2}{|l|}{ الارجة الكلية } \\
\hline
\end{tabular}


يتضح من الجدول رقم (1) أن متوسط ممارسة القيادة التشاركية في الجامعات السعودية

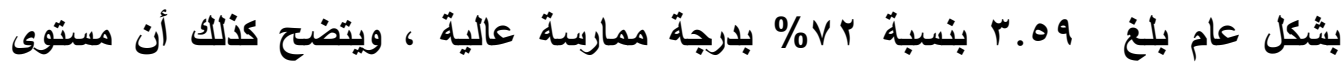

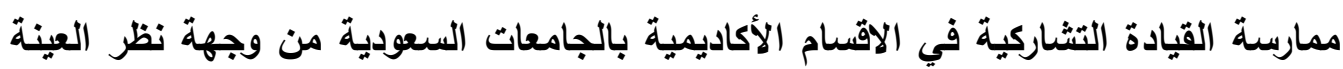

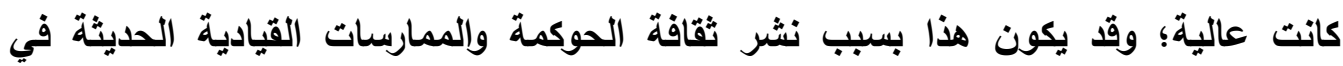
الأقسام الأكاديمية في الجامعات، وقد يعود لنشر ثثقافة الإدارة الأتية في الأقسام الأكاديمية بالجامعات التي تؤكد على التشاركية والتعاون في الإدارة بين جميع الأطراف في القسم الأكاديمي، ويلاحظ أيضاً أن مجال المشاركة في صناعة القرار حصل على المرتبة الأولى الجى بمتوسط Y, Y بارجة ممارسة عالية، وقد يعزى ذلك إلى إثرالك جميع أعضاء هيئة التدريس في القسم الأكاديمي في حضور مجلس القسم والمشاركة في صناعة القرارات التي يتخذها القسم كون أغلب قرارات القسم تحسم بالتصويت والمشاركة من جميع الأعضاء، وجاء بالمرتبة الأخيرة مجال الاتصال ويناء المعلومات بمتوسط ب ع بـ ودرجة ممارسة عالية، وقات يعزى ذلك بسبب مرونة التواصل بين أعضاء هيئة التدريس في الأقسام الأكاديمية، واستخدام رئيس القسم الاتصال الرسمي وغير الرسمي مع أعضاء القسم وطبيعة التواصل والاتصال بين رئيس القسم وأعضاء القسم عبر قتوات مفتوحة ومتعددة ويالذات مع انتشار وسائل التواصل الاجتماعي، وتتفق نتيجة هذه الدراسة بشكل جزئي في مجال المشاركة في صناعة

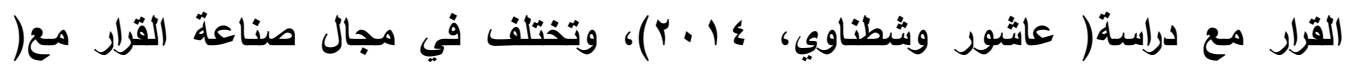

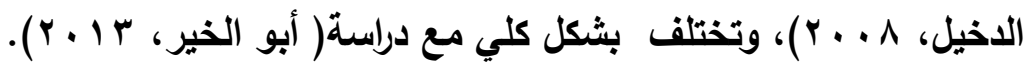


درجة ممارسة القيادة التشاركية وعلاقتها بالمناخ المنظمي في الأقسام الأكاديمية بالجامعات السعودية.

\section{ثانياً : درجة ممارسة القيادة التشاركية لفقرات كل مجال من مجالاتها :}

ا 1 -درجة القيادة التشاركية لمجال المشاركة في صناعة القرار :

جدول (ץ)المتوسطات والانحرافات المعيارية لارجة ممارسة القيادة التثاركية المتعلقة بمجال المشاركة في صناعة القرار

\begin{tabular}{|c|c|c|c|c|c|c|}
\hline الترتيب & الممارسة & 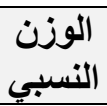 & المعياري & الحسابي & مجال المشاركة في صناعة القرار & p \\
\hline 1 & 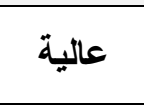 & 0.78 & 1.06 & 3.88 & 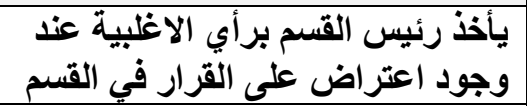 & 0 \\
\hline$r$ & عالية & 0.76 & 0.99 & 3.81 & أيعضاء رئيسة التدريس فلى مشي انجاركة المهام & $r$ \\
\hline$r$ & 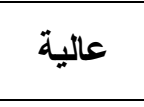 & 0.76 & 1.02 & 3.79 & في القي رئيس عند تقفيض في الخبراتة المجودة & 7 \\
\hline$\varepsilon$ & 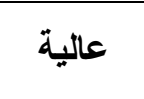 & 0.75 & 0.97 & 3.77 & أيلير رئيس ديمقراطي القسم الجلسات وفق & 1. \\
\hline 0 & 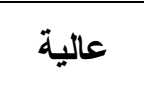 & 0.74 & 0.93 & 3.69 & يحترم رئيس لرأيه. القسم وجهات النظر & 9 \\
\hline 7 & عالية & 0.74 & 1.03 & 3.68 & 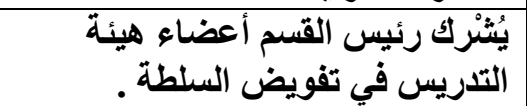 & 1 \\
\hline v & عالية & 0.73 & 0.98 & 3.66 & فتي تفويض اجتماعات السلطة بالقموضوعية & $\wedge$ \\
\hline$\wedge$ & 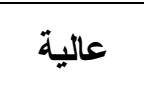 & 0.73 & 1.07 & 3.65 & 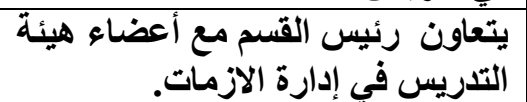 & $r$ \\
\hline 9 & عالية & 0.73 & 1.07 & 3.63 & للمن قبل أعضيس القضاء هيئة التّلويس المطروحة & $\varepsilon$ \\
\hline 1. & 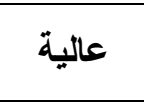 & 0.70 & 1.03 & 3.51 & 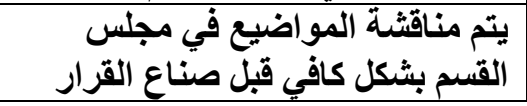 & v \\
\hline \multicolumn{2}{|c|}{ عالية } & 0.74 & 0.86 & 3.71 & المجموع & \\
\hline
\end{tabular}

يتبين من الجدول( r ) المتوسطات الحسابية والانحرافات المعيارية لارجة ممارسة القيادة التشاركية في الاقسام الأكاديمية بالجامعات السعودية المتعلقة بمجال المشاركة في صناعة القرار بلرجة عالية حيث بلغ المتوسط الحسابي لهذا المجال V.VI، وهذا يشير إلى أن أفراد عينة البحث يرون أن رؤساء الأقسام الأكاديمية يمارسون المشاركة في صناعة القرار بلرجة عالية وريما يرجع ذلك إلى كون القرارات تتخذ في الأقسام بعد التشاور والتصويت عليها،

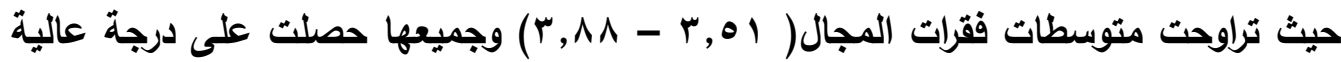




\section{درجة ممارسة القيادة التشاركية وعلاقتها بالمناخ المنظمي في الأقسام الأكاديمية بالجامعات السعودية.}

، مما يثبت أن هناك مشاركة وتعاون بين رئيس القسم الأكاديمي وأعضاء القسم في صناعة القرارات المتعلقة بالقسم، كما يلاحظ حصول الققرة الخامسة "يأخذ رئيس القسم برأي الاغلبية عند وجود اعتراض على القرار في القسم"؛ على الترتيب الأول بمتوسط ^^.ب ودرجة عالية، ريما يعود ذلك إلى طبيعة القرارات التي يتم اتخاذها في القسم تكون عن طريق اجتماع موسع يسمى مجلس القسم يحضره جميع الأعضاء فيه وحسب اللوائح الأكاديمية يتم إخضاع مواضيع وقرارات مجلس القسم للتصويت ويحدد في اللائحة يتم الموافقة على أي قرار في مجلس القسم إذا بلغ عدد الموافقين من الأعضاء أكثر من نصف أعضائه بحيث تثكل أغلبية ورئيس القسم يضم صوته ويأخذ برأي الأغلبية ، وتأتي بالمرتبة الأخيرة الققرة السابعة "يتم مناقشة المواضيع في مجلس القسم بشكل كافي قبل صناعة القرار "؛ حيث بلغ متوسطها 1. r. ويدرجة عالية، وقد يعزى حصولها على المرتبة الأخيرة رغم أن درجة ممارستها عالية بسبب ضيق وقت الاجتماعات في مجلس القسم مما قد لا يوجد الوقت الكافي لمناقشة القرارات مناقشة مستقيضة قبل اتخاذها، ويالذات عندما تكون عدد المواضيع التي تتطلب إصدار قرار كثيرة ومتنوعة، أو قد يكون بسبب الاختلافات التي قـ تحصل في وجهات نظر أعضاء هيئة التدريس في القسم حول تلك القرارات التي يمكن أن تؤجل دون وينتهي وقت الجلسة دون توافق عليها. تتفق نتيجة هذا البحث بشكل جزئي في مجال المشاركة في صناعة القرار مع دراسة( عاثور وشطناوي، ؛ ( ـ ب)، وتختلف في مجال صناعة القرار مع

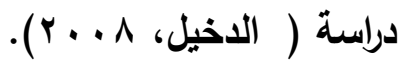


r - برجة القيادة التشاركية لمجال تقويض السلطة :

جدول (ץ) المتوسطات والانحرافات المعيارية لدرجة القيادة التثاركية المتعلقة بمجال تفويض السلطة

\begin{tabular}{|c|c|c|c|c|c|c|}
\hline 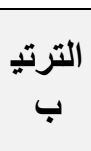 & الممار & 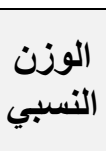 & 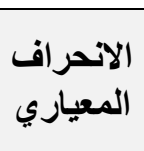 & المستوسط & مجال تفويض السلطة & \\
\hline 1 & عالية & 0.80 & 0.99 & 3.99 & 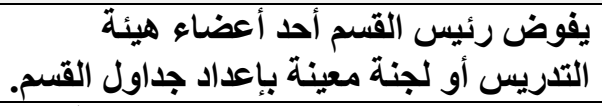 & $r$ \\
\hline r & عالية & 0.73 & 1.01 & 3.64 & 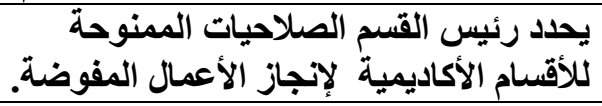 & $\varepsilon$ \\
\hline$r$ & عالية & 0.73 & 0.99 & 3.63 & يفوض رئيس القسم بعض أسرع. اعماله بهـف & 1 \\
\hline$\varepsilon$ & عالية & 0.74 & 0.90 & 3.69 & 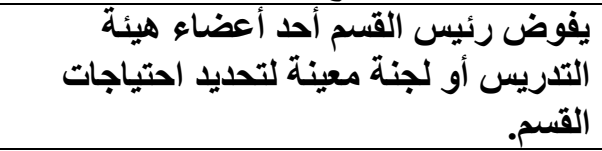 & $r$ \\
\hline 0 & عالية & 0.72 & 1.08 & 3.58 & 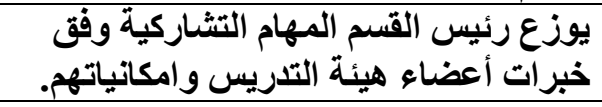 & 0 \\
\hline 7 & عالية & 0.71 & 1.01 & 3.54 & ازدوزعية في الأدوار العمل بحيث لا تحدث & 7 \\
\hline \multicolumn{2}{|c|}{ عالية } & 0.74 & 0,78 & 3.68 & المتوسط & \\
\hline
\end{tabular}

يتضح من الجدول ( r ) المتوسطات الحسابية والانحرافات المعيارية لارجة ممارسة القيادة التشاركية في الاقسام الأكاديمية بالجامعات السعودية في مجال تفويض السلطة جاء بدرجة

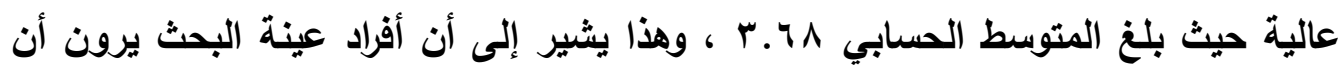

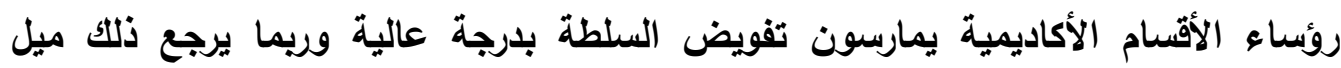
رؤساء الأقسام لتوزيع الأعمال على أعضاء هيئة التدريس بما يتناسب مع قدراتهم

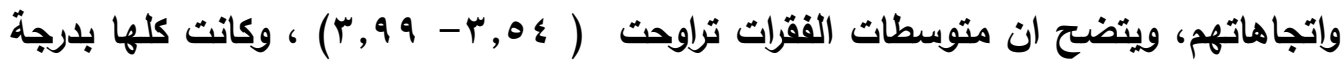
عالية، فقد حصلت الفقرة الثالثة " يفوض رئيس القسم أحد أعضاء هيئة التريس أو لجنة

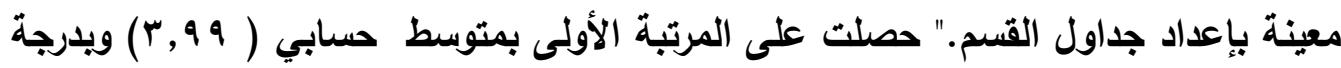
عالية ، وقد يعود إلى وجود مقرر لكل قسم أكاديمي يتم اختياره من أعضاء هيئة التدريس

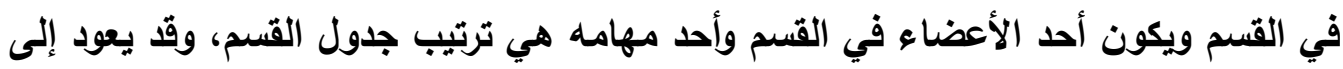

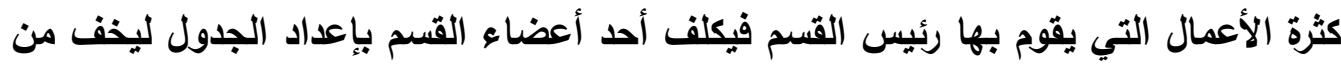
الأعباء التي يتحملها ويجسد المشاركة والتعاون في إدارة شؤون القسم، وحصلت على 
المرتبة الأخيرة الفقرة السادسة "يوزع رئيس القسم العمل بحيث لا تحدث ازدواجية في الأدوار

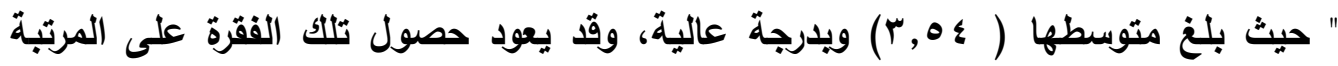
الأخيرة من وجهة نظر العينة بسبب وجود بعض الازدواجية في الأدوار ولكنها في حالات

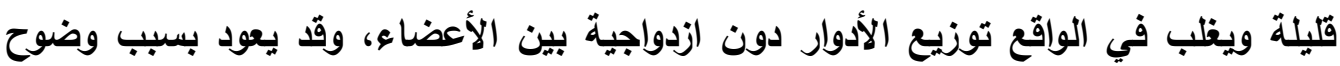
مهام رئيس القسم ووضوح أدوار أعضاء هيئة التدريس في القسم وهناك لوائح وإنظمة تحدد أدوار كل فرد من القسم العلمي وقد يحدث أحياناً ضعف في الاطلاع على تلك اللوائح من قبل رئيس القسم أو الأعضاء فيحدث ازدواجية في الأدوار ولكنها تظل قليلة. وتتثق هذه النتجة

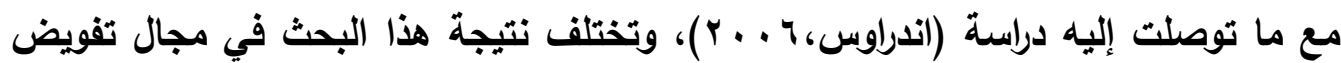

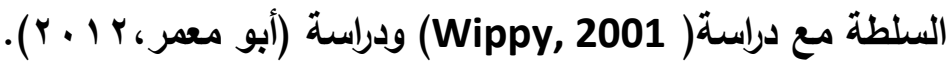

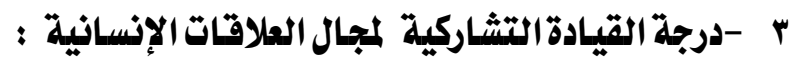

جدول ( ) المتوسطات والانحرافات المعيارية درجة القيادة التشاركية لمجال العلاقات الإنسانية

\begin{tabular}{|c|c|c|c|c|c|c|}
\hline ب بترتي & سلمة المَّ & النسبن & المعياري & الحستوسي & العلاقات الإنساتية & \\
\hline 1 & عالية & 0.74 & 1.08 & 3.70 & التذريس. رئيس القسم في حل مشاكل أعضاء هيئة & r \\
\hline r & عالية & 0.73 & 1.03 & 3.64 & يحثر رئيس القسم على التعاون بين أعضاء هيئة & $r$ \\
\hline$r$ & عالية & 0.73 & 1.11 & 3.63 & يوفر رئيس القسم جواً يسوده المحبة في القسم. & 1 \\
\hline$\varepsilon$ & عالية & 0.71 & 1.11 & 3.57 & يحراملين. رئيس القسم على رفع الروح المعنوية & $\varepsilon$ \\
\hline 0 & عالية & 0.68 & 1.01 & 3.42 & 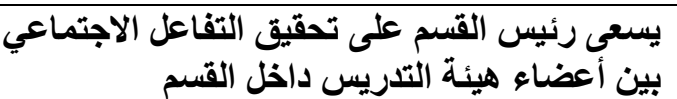 & 0 \\
\hline 7 & عالية & 0.68 & 1.02 & 3.42 & أيحضاء هيئة التّريس القسم على العلاقات الاجتماعية مي & $r$ \\
\hline V & متوسط & 0.66 & 1.03 & 3.32 & الأكاديمية رئيس القسم بتطوير الجاتب المهني للأقسام & 7 \\
\hline \multicolumn{2}{|c|}{ عالية } & 0.73 & 1.06 & 3.53 & المجموع & \\
\hline
\end{tabular}

يوضح الجدول رقم (؛) المتوسطات الحسابية والانحرافات المعيارية لارجة ممارسة القيادة التشاركية في الاقسام الأكاديمية في الجامعات السعودية في مجال العلاقات الإنسانية جاء بدرجة عالية حيث بلغ المتوسط الحسابي r. r. ، وهذا يشير إلى أن أفراد عينة البحث يرون أن رؤساء الأقسام الأكاديمية يمارسون العلاقات الانسانية بلرجة عالية وريما يرجع 
ذلك الاحترام التقدير المتبادل بين رؤساء الأقسام وأعضاء هيئة التدريس، وتراوحت متوسطات

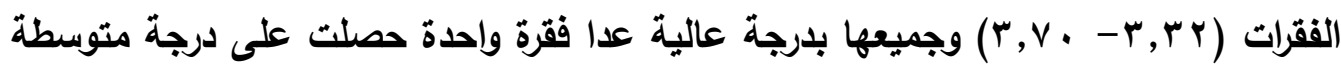
، حيث حصلت الفقرة الثانية " يجته رئيس القسم في حل مشاكل أعضاء هيئة التريس. " على المرتبة الأولى بمتوسط ( r,V) ويدرجة ممارسة عالية وقد يعود إلى شعور رؤساء الأقسام الأكاديمية بأهمية التعاون مع أعضاء هيئة التدريس في القسم وحل مشكلاتهم الأكاديمية المختلفة الني قد تواجههم ، وقد يكون هذا بسبب عمق الاحترام والتقدير المتبادل والتعاون بين رئيس وأعضاء القسم، بينما حصلت الفقرة السابعة " يهتم رئيس القسم بتطوير الجانب المهني للأقسام الأكاديمية" على المرتبة الاخيرة بمتوسط (ץ, r,ץ)، ويلرجة ممارسة متوسطة؛ وريما يعزى ذلك إلى أن التنمية المهنية لأعضاء هيئة التدريس في القسم الأكاديمي تتطلب إعداد برامج تدريبية متنوعة في التنمية المهنية وهذه البرامج المسؤول عن إعدادها وتقديمها مراكز التدريب في الكلية أو الجامعة أو مراكز التطوير والتنمية البشرية في الجامعة وليست مسؤولية رئيس القسم مع انه يثارك بجزء بسيط من خلال تقايم مقترحات للقائمين على مراكز التدريب بطلب برامج تدريبية للتنمية المهنية لأعضاء القسم، وريما يعود إلى ضعف صلاحيات رؤساء الأقسام الأكاديمية في التنمية والتظوير المهني للقسم الذي يتطلب إمكانيات في إعدادها وتنفيذها، وقد يعود لكثرة أعباء رئيس القسم متمثلة بالأعمال الإدارية الروتينية التي قد تعيق من متابعة مستوى التنمية المهنية لأعضاء هيئة التدريس وتنفيذ برامج التطوير والتنمية المهنية لأعضاء هيئة التدريس في القسم، وتتفق هذه النتيجة مع ما توصلت إليه دراسة (الاشقرومونس، r I • r ) 
درجة ممارسة القيادة التشاركية وعلاقتها بالمناخ المنظمي في الأقسام الأكاديمية بالجامعات السعودية.

ع - درجة القيادة التشاركية لمجال الاتصال وبناء المعلومات :

جدول (•) المتوسطات والانحر افات المعيارية لارجة ممارسة القيادة التشاركية المتعلقة بالاتصال

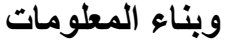

\begin{tabular}{|c|c|c|c|c|c|c|}
\hline ابترتي & الممار & 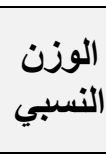 & 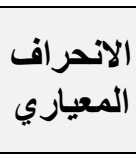 & المتوسط & الاتصال ويناء المعلومات & \\
\hline 1 & عالية & 0.73 & 0.95 & 3.66 & الرستخدم رئيس أعضاء هيئة التّال الرسيس. & $V$ \\
\hline$r$ & عالية & $\mathbf{0 . 7 0}$ & 0.98 & 3.52 & 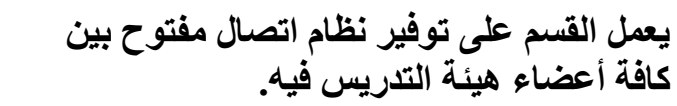 & 1 \\
\hline$r$ & عالية & 0.69 & 1.05 & 3.44 & هيئة التدريس. القسم ان يكون الاتصال متبادل بين أعضاء & 7 \\
\hline$\varepsilon$ & عالية & 0.69 & 1.05 & 3.43 & تتسم الاتصالات التثاركية داخل القسم بالمرونة. & $\wedge$ \\
\hline 0 & متوسط & 0.68 & 1.02 & 3.38 & ستم استخد توفير وسائل التقنية الحديثة في عملية & $\mu$ \\
\hline 7 & متوسط & 0.67 & 1.10 & 3.35 & الاتصال وبناء المعلو وسائل الاتصال . الديثة في عملية & $\varepsilon$ \\
\hline$v$ & متوسط & 0.66 & 1.04 & 3.32 & يقدم القسم المعلومات اللازمة في الوقت المناسب. & 0 \\
\hline$\wedge$ & متوسط & 0.65 & 1.06 & 3.24 & للمعلم القمات دليلاً ارشادياً عن كيفية الوصول & r \\
\hline \multicolumn{2}{|c|}{ عالية } & 0.68 & 0.98 & 3.42 & 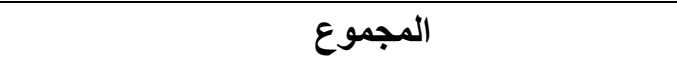 & \\
\hline
\end{tabular}

يتضح من الجدول رقم (0) أن المتوسطات الحسابية والانحرافات المعيارية لارجة فقرات ممارسة القيادة التشاركية في مجال الاتصال ويناء المعلومات جاء بلرجة عالية حيث بلغ المتوسط الحسابي Y ؟.ب ، وهذا يشير إلى أن أفراد عينة البحث يرون أن رؤساء الأقسام الأكاديمية يمارسون الاتصال ويناء المعلومات بلرجة عالية وريما يرجع ذلك لاستخدام رؤساء الأقسام لوسائل التواصل الحديثة مع أعضاء هيئة التدريس ووجود قنوات اتصال رسمية وغير

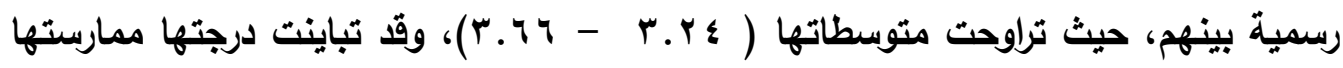
ما بين العالية والمتوسطة؛ فقد حصلت الفقرة السابعة " يستخدم رئيس القسم الاتصال 
الرسمي وغير الرسمي مع أعضاء هيئة التدريس "؛ هصلت على المرتبة الأولى بدرجة

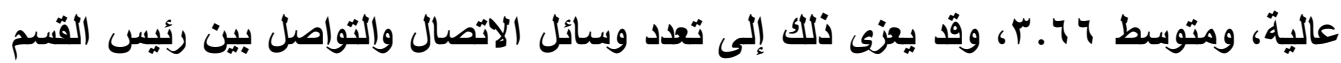
وأعضاء هيئة التاريس، وقد يعود ذلك نتيجة العلاقات الإنسانية السائدة بين رئيس القسم وأعضاء القسم القائمة على التعاون والاحترام المتبادل مما تذوب الرسميات والاقتصار على التواصل الرسمي إلى تعدد وسائل التواصل المتتوعة الغير رسمية وأوقات مختلفة وليست مقتصرة بوقت الدوام الرسمي فقط وقد يساعد هذا إلى إنجاح العمل بشكل كبير، بينما حصلت الفقرة الأولى " يقدم القسم دليلاً ارشادياً عن كيفية الوصول للمطلومات "، على المرتبة الاخيرة بمتوسط ؟ ؟.r ويلرجة ممارسة متوسطة، مما يلال أن القسم لا يهتم بطباعة أدلة إرشادية وتوزيعها للمستفيدين من خدمات الجامعة تسهل لهم طريقة الحصول على المعلومات والوصول إليها بسهولة ويسر، وريما يعود إلى أن إعداد الأدلة الإششادية والمطبوعات ليست مسؤولية الأقنسام الأكاديمية بالجامعات ولكنها مسؤولية إدارة النظم والمعلومات في الجامعة،

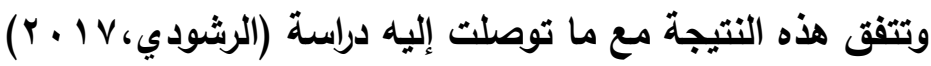

النتيجة المتماقلة بالتساؤل الثاذي ؛ ما المعوقات التي تواجه ممارسة القيادة التثاركية في الأقسام الأكاديمية بالجامعات السعودية؛

للإجابة على هذا السؤال تم استخدام المتوسط الحسابي والاتحراف المعياري والوزن النسبي لارجة معوقات القيادة التشاركية في الاقسام الأكاديمية بالجامعات السعودية للارجة الكلية للمعوقات وفقراتها، ورتبت الفقرات حسب المتوسط الحسابي والحكم على درجة المعوق للقيادة التشاركية ، ويتضح ذلك في الجدول رقم (؟) الآتي : 
درجة ممارسة القيادة التشاركية وعلاقتها بالمناخ المنظمي في الأقسام الأكاديمية بالجامعات السعودية. جدول(؟)المتوسطات والانحرافات المعيارية لارجة معوقات القيادة التشاركية للأقسام الأكاديمية في الجامعات السعودية

\begin{tabular}{|c|c|c|c|c|c|c|}
\hline الترتي & قدجة & النسبن & الالحرا & المتوسط & 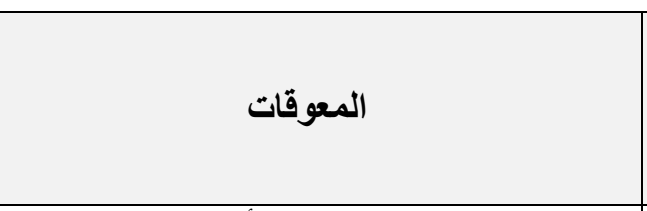 & p \\
\hline$\varepsilon$ & عالية ع الية & 0.70 & 1.02 & 3.50 & بالعمل التشاركي. من الناجم تداخل الأدوار عند القيام & 1 \\
\hline $\mathrm{V}$ & عالية & 0.68 & 1.08 & 3.42 & النظرة السلبية تجاه العمل الجماعي التشاركي. & $r$ \\
\hline r & 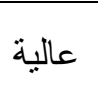 & 0.71 & 1.21 & 3.54 & الأدوار أو التوجهة منولد الصراعات نتيجة الاختلاف في & $r$ \\
\hline 1 . & 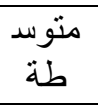 & 0.61 & 1.37 & 3.07 & | ميل رئيس القسم نحو التسلط في إدارته. & $\varepsilon$ \\
\hline 9 & 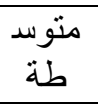 & 0.66 & 1.29 & 3.28 & قالمسؤئيس الفيم من تفويض الصلاحيات أو & 0 \\
\hline r & 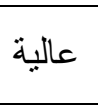 & 0.74 & 1.30 & 3.70 & |المشاركة في الاعمالة أعضاء هالإريئة التّريس نحو & 7 \\
\hline 1 & 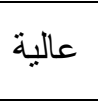 & 0.80 & 0.85 & 4.01 & التدريس. الاعباء الملقاة على عاتق أعضاء هيئة & $\mathrm{V}$ \\
\hline 7 & 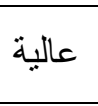 & 0.68 & 1.07 & 3.42 & وقت للمشاركة. للسرة في اتخاذ القرار، مما لا يتيح & $\wedge$ \\
\hline 0 & 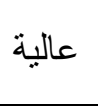 & 0.69 & 1.05 & 3.43 & لمفهوم وممعارسات الثيادة التهاء التشاركية بالقدر الكافي & 9 \\
\hline$\wedge$ & 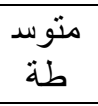 & 0.66 & 1.08 & 3.32 & تجاه المشـاركةة. & ! \\
\hline \multicolumn{2}{|c|}{ عالية } & 0.69 & 0.80 & 3.47 & المجموع & \\
\hline
\end{tabular}

يتضح من الجدول رقم (†)أن درجة معوقات تطبيق القيادة التشاركية في الاقسام

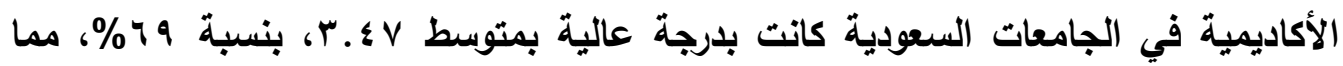
يلال أن هناك صعويات ومعوقات عالية تواجه ممارسة القيادة التشاركية في الاقسام الأكاديمية في الجامعات السعودية وقد يعود ذلك إلى نمط المركزية الإدارية القائم في إدارة الكليات مما ينعكس على ممارستها في الأقسام الأكاديمية، وقد يعزى لحداثة مفهوم القيادة التشاركية وتحتاج إلى ترسيخها كممارسة ناجحة وقت طويل لنشر ثقافة القيادة التشاركية في الاقسام الأكاديمية، وقد يعزى لمقاومة رؤساء الأقسام لممارسة نمط القيادة التشاركية قد يعود لسوء 
الفهم منهم بأنها ستحد من صلاحياتهم وسلطاتهم الإدارية في ظل تمركز مفهوم اللامركزية، ويلاحظ من الجدول المتوسطات الحسابية لارجة معوقات تطبيق القيادة التشاركية التي

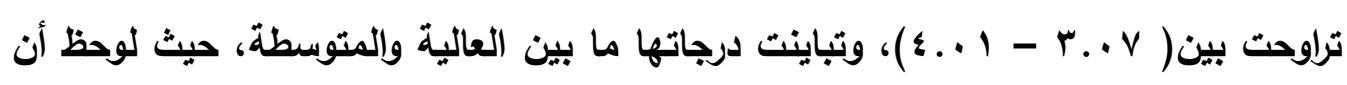

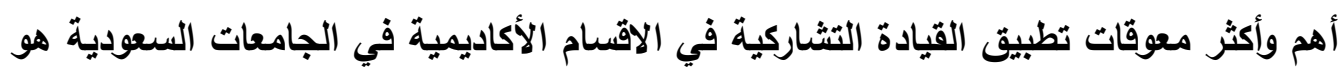

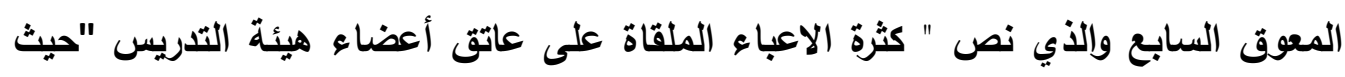

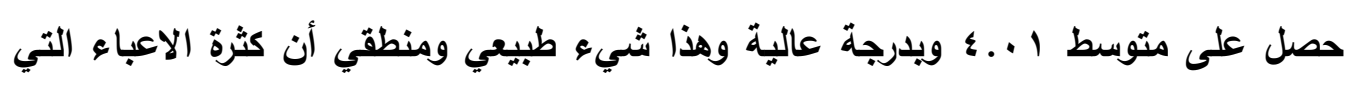
يقوم بها عضو هيئة التدريس من أعباء تدريسية واعباء بحثية وكثثرة عدد ساعات التدريس

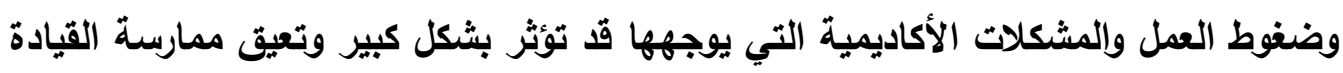
التثاركية فالكثير من أعضاء هيئة التدريس في القسم يعتذر عن حضور جلسات القسم بسبب تعارضها مع الأعمال والمهام التي يقوم بها.

ويلاحظ أن المعوق الرابع "ميل رئيس القسم نحو التسلط في إدارته"، حصل على

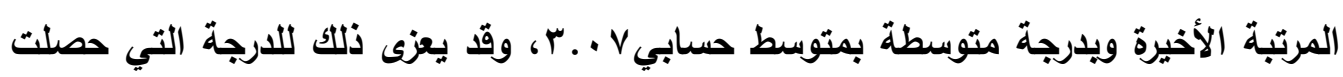

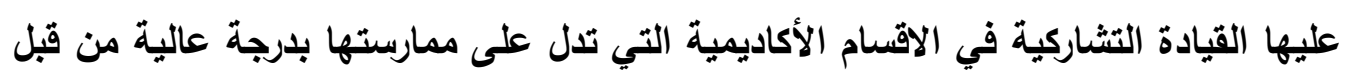

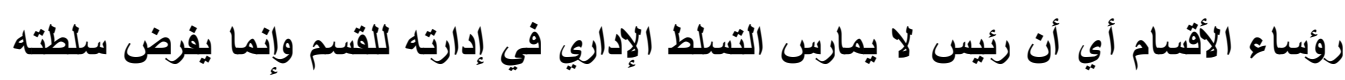

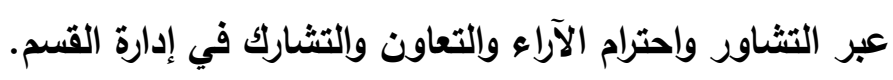

النتائج المتعلقة بالتساؤل الثالث: هل توجد فروق ذات دلالة إحصائية عند مستوى (ه ...) بين استجابات أفراد عينة البحث حول درجة ممارسة القيادة التثاركية في الأقسام الأكاديمية

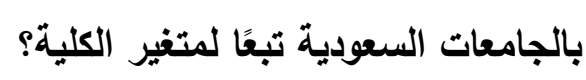

متغير الكلية : للإجابة عن السؤال بالجزء المتعلق بمتغير الكلية تم استخدام اختبار ت

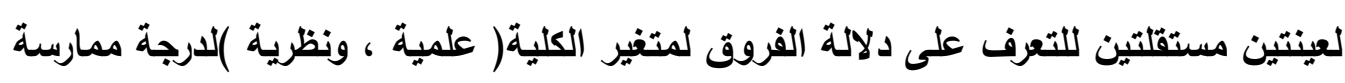

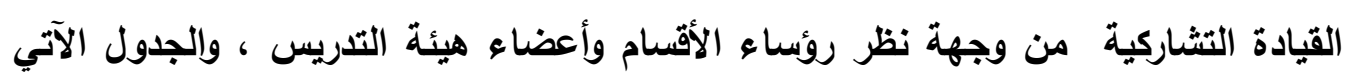

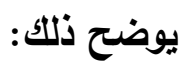


جدول (V)(ختبار ت لعينتين مستقلتين لاختبار الفرق بين متوسطات درجات متغير الكلية في درجة ممارسة القيادة التثاركية

\begin{tabular}{|c|c|c|c|c|c|c|c|c|}
\hline الدلالة & مستوى & قيمة ت & الحرية & المعياري & المسابي & العدد & الكلية & المجال \\
\hline \multirow{3}{*}{ دالة } & \multirow{3}{*}{0.00} & \multirow{3}{*}{ 5.40- } & \multirow{3}{*}{1195} & 0.92 & 3.58 & 647 & علمية & \multirow{3}{*}{ في صنارعة المثرار } \\
\hline & & & & & & & & \\
\hline & & & & 0.78 & 3.85 & 550 & نظرية & \\
\hline \multirow{2}{*}{ غالة } & \multirow{2}{*}{0.053} & \multirow{2}{*}{ 1.94- } & \multirow{2}{*}{1195} & 0.84 & 3.64 & 647 & علمية & \multirow{2}{*}{ تفويضة } \\
\hline & & & & 0.71 & 3.73 & 550 & نظرية & \\
\hline \multirow{2}{*}{ دالة } & \multirow{2}{*}{0.00} & \multirow{2}{*}{ 6.14- } & \multirow{2}{*}{1195} & 1.01 & 3.38 & 647 & علمية & \multirow{2}{*}{ الإنساتية } \\
\hline & & & & 0.77 & 3.70 & 550 & نظرية & \\
\hline \multirow{2}{*}{ دالة } & \multirow{2}{*}{0.01} & \multirow{2}{*}{$2.74-$} & \multirow{2}{*}{1195} & 0.91 & 3.36 & 647 & علمية & \multirow{2}{*}{ الاتصال } \\
\hline & & & & 0.77 & 3.49 & 550 & نظريـة & \\
\hline \multirow{2}{*}{ دالة } & \multirow{2}{*}{0.00} & \multirow{2}{*}{ 4.70- } & \multirow{2}{*}{1195} & 0.84 & 3.49 & 647 & علمية & \multirow{2}{*}{ الكلي } \\
\hline & & & & 0.69 & 3.70 & 550 & نظرية & \\
\hline
\end{tabular}

يتضح من الجدول(V) نتيجة اختبار (ت) للتعرف على دلاية الفروق في درجة

ممارسة القيادة التشاركية في الجامعات السعودية تبعاً لمتفير الكلية، ويلاحظ من الجدول أن قيمة (ت) دالة إحصائياً عند مستوى دلالة ه... . للارجة الكلية لممارسة القيادة التثاركية في الاقسام الأكاديمية بالجامعات السعودية ولجميع المجالات عدا مجال ( تفويض السلطة ) لم تكون هناك فروق دالة إحصائياً، ويتضح من الجدول أن الفروق كانت لصالح الكليات النظرية الني كاتت متوسطها أكثر من متوسط الكليات العلمية، وقد يعى ذلك 
لاختلاف آلية العمل الإداري في الكليات النظرية والكليات العلمية؛ ففي الكليات النظرية يخف العمل التدريسي لرؤساء الأقسام مما يهتم بممارسة العمل الإداري بينما رؤساء الأقسام في الكليات العلمية يعاني من زيادة الأعباء والنصاب التدريسي أكثر من العمل الإداري، وقد يعود إلى أن موضوع القيادة التشاركية موضوع تريوي واجتماعي يقدم في بعض الكليات النظرية مثل التربية والعلوم الإدارية كمفهوم من مفاهيم الإدارة والقيادة وهم أكثر اطلاعاً على هذا الموضوع أكثر من الاساتذة في الكليات العلمية مما يكون هناك وعي في استخدام القيادة التشاركية في الاقسام الأكاديمية في الكليات النظرية بينما في الكليات العلمية وجود قصور في الاطلاع على موضوع القيادة التشاركية مما ينعكس على ممارستها ، وريما يعود ذلك إلى كثرة الأعمال العلمية والبحثية في الاقسام الأكاديمية في الكليات العلمية مما يجد صعوية في ممارسة القيادة التشاركية ، وقلة تقلد أعضاء هيئة التدريس بالكليات العلمية المناصب القيادية والادارية وممارسة العمل الاداري نظراً لقلة عددهم وكثرة أعباءهم التدريسية ، وقد يكون هذا بسبب كثرة أعضاء هيئة التدريس في الكليات النظرية الانسانية والاجتماعية عنه في الكليات العلمية مما ينعكس التشاركية في الاقسام الأكاديمية ، ويعود أيضاً إلى اختلاف آلية التواصل بين رؤساء الأقسام وأعضاء هيئة التدريس في الكليات العلمية والنظرية ففي الكليات النظرية هناك تواصل بين رؤساء الأقسام وأعضاء هيئة التدريس عبر قنوات التواصل المختلفة بما يخدم مصلحة القسم، ومن الجدول يتضح أنه لا توجد فروق ذات دلالة إحصائية بين الكليات العلمية والنظرية في ممارسة القيادة التشاركية بالمجالات( تفويض السلطة)، وقد يعزى ذلك لتفويض رؤساء الأقسام زملائهم ببعض المهام سواء كان في الكليات العلمية أو النظرية فإن رئيس القسم يفوض بعض صلاحياته لأحد أعضاء القسم لمساعدته لكثرة الأعباء التي يتحملها. 
التوصيات:

$$
\text { في ضوء نتائج البحث، يوصي الباحث بالآتي: }
$$

ا-تفيل اللوائح والقوانين والأنظمة في الأقسام الأكاديمية بالجامعات وإشرالك جميع المعنيين ومنتسبين القسم من أعضاء هيئة التدريس في تفعيل تلك اللوائح.

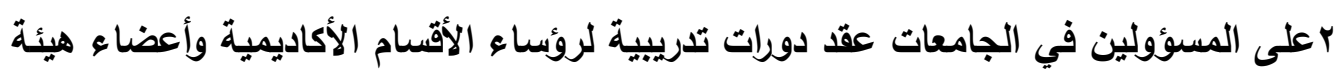
التدريس لتنمية مهارات القيادة التشاركية ومفهومها وأهميتها وكيفية ممارستها وتوضيح طرق وآلية ممارستها.

ب-على المسؤولين في القيادة العليا في الجامعات إتاحة الفرصة لرؤساء الأقسام الأكاديمية بالجامعات المشاركة بالمؤتمرات والندوات العلمية على المستوى المحلي والخارجي المتعلقة بالقيادة التشاركية.

ع -تفعيل نظام التقييم المستمر والمتابعة المستمرة لمدى تطبيق معايير القيادة التشاركية في الاقسام الأكاديمية من قبل رؤساء الأقسام وأعضاء هيئة التدريس. ه-تخصيص مكافآت مادية ومعنوية تشجيعية لرؤساء الأقسام وأعضاء هيئة التدريس في الأقسام الأكاديمية المتميزون في تطبيق القيادة التشاركية والمشاركة الفاعلة في المهام

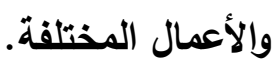

צ-تفعيل مبدأ الثواب وإلعقاب ومحاسبة المقصرين من رؤساء الأقسام الأكاديمية في أعمالهم ومكافأة المتميزين بما يسهم في تطبيق القيادة التشاركية. V-تثجيع رؤساء الأقسام وأعضاء هيئة التدريس في الأقسام الأكاديمية بالجامعات للمشاركة في زيارة جامعات متطورة للتعرف على واقع ممارسة القيادة التشاركية في تلك الجامعات للاستفادة منها بما يخدم ممارستها في جامعاتهم. 
1-على المسؤولين في الجامعات تعيين أعضاء هيئة التدريس جدد في الأقسام الأكاديمية التي تعاني من نقص في الكادر الأكاديمي حتى تقلل الأعباء الملقاة على عاتق أعضاء هيئة التّريس بما يمكنهم من المشاركة في المهام المختلفة في القسم.

9-تشجيع أعضاء هيئة التدريس في الأقسام الأكاديمية في المشاركة في الأعمال الإدارية لأن أي أحد منهم قد يتولى مسؤولية إدارة القسم فعندما يشارك عضو هيئة التدريس في العمليات الإدارية في القسم يكتسب خبرات إدارية يستفيد منها عندما يتولى رئاسة القسم. • 1-على رئيس القسم توزيع المهام والأدوار على أعضاء هيئة التدريس في القسم بالعدل دون تمييز وحسب إمكانات ورغبات الأعضاء حنى لا تتتج صراعات بينهم بما يضمن تحقيق عدم وجود تداخل في المهام والأعمال الموكلة إليهم. 


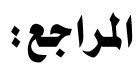

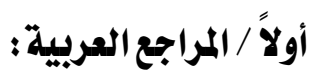

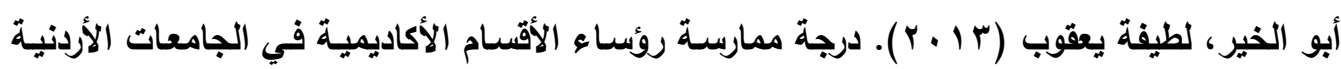

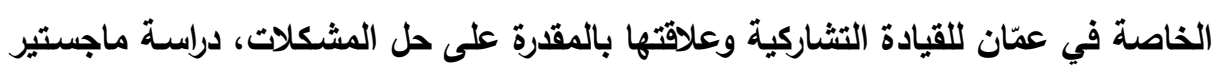
(غير منشورة)، جامعة الثرق الأوسط، عمّان.

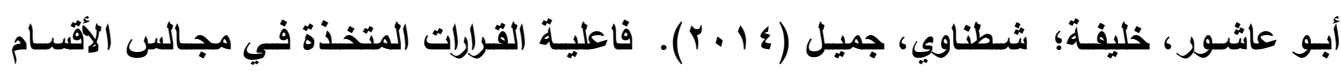

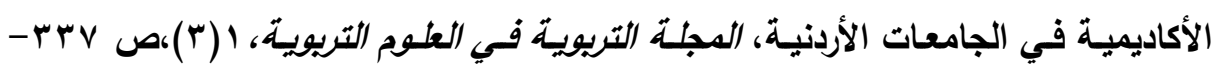

. $r \leqslant 9$

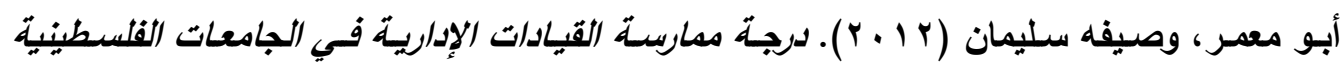

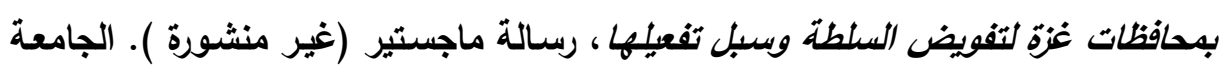
الإسلامية، كلية التربية، غزة.

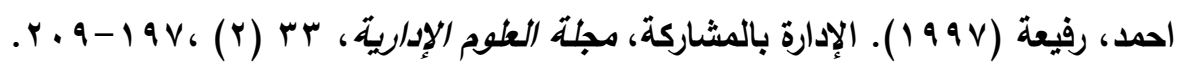

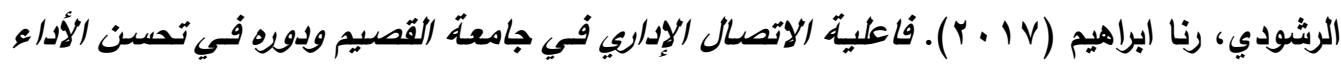

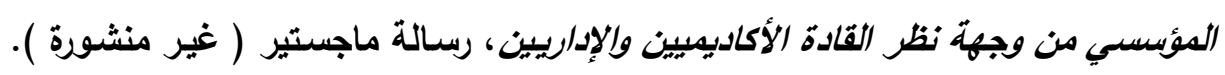
جامعة ام القرى، كلية التربية، مكة المكرمة.

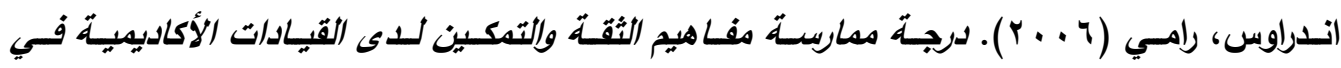
الجامعات الأرنية الرسمية ، رسالة دكتوراه (غير منشورة)، الجامعة الاردنية، عمان.

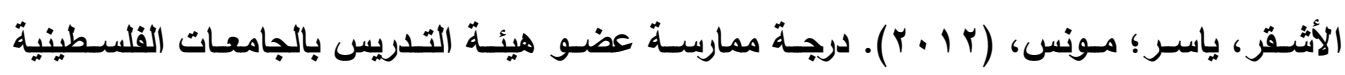

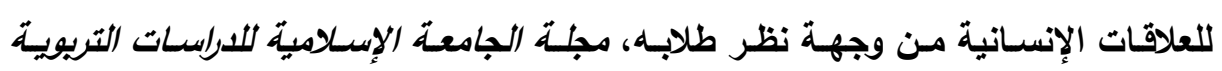

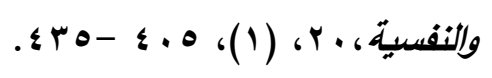


البطل، منى (9 . . r). تكنولوجيا الاتصالات المعاصرة الشخصية والإدارية ونظم المعلومات، القاهرة: دار النهضة العربية.

سويدان، طارق؛ العدلوني، محمد (r . ب). إدارة الوقت ، الرياض: دار بن جزنن للنشر والتوزيع. الحربي، قاسم نائل (^ . ץ). القيادة التريوية الدعاصرة، الأردن: دار الجنادرية النشر. الدخيل، عبدالله (^ . . ץ). درجة مشاركة أعضاء هيئة التدريس في صناعة القرارات الخاصة بشؤون القسم وشؤون أعضاء هيئة التدريس وشؤون الطلاب بكليات المعلمين في السعودية، مجلة

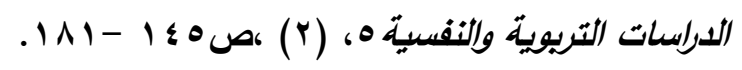

الصيرفي، محمد (9 . . ؟ ). الموسوعة العلمية للسلوك التنظيسي التحليل على مستوى المنظمات، القاهرة: المكتب الجامعي الحديث.

عياصرة، علي احمد († . ץ). القيادة وإلدافعية في الاد/رة التريوية، رسالة ماجستير (غير منشورة)، الجامعة الاردنية، كلية العلوم التريوية، عمان .

عبيدات، ذوقان؛ وعدس، عبدالرحمن؛ وعبدالحق، كايد (0 1 ب). البحث العلمي: مفهومه، أدواته،

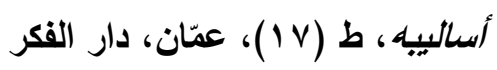

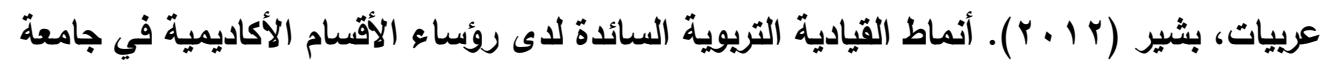
بقعاء التطبيقية وأثرها على الأداء الوظيفي لأعضاء هيئة التدريس، مجلة الجامعة

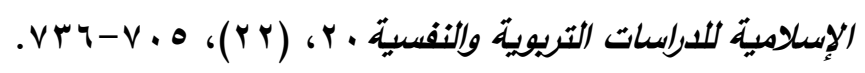

العرابيد، نبيل أحمد( • ( ץ). دور القيادة التشاركية بدليريات التريبية والتعليم في حل مشكلات مديري

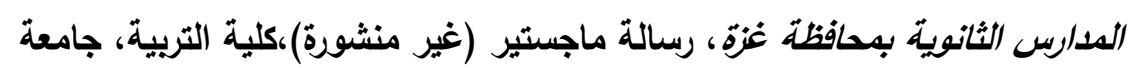
الأزهر.

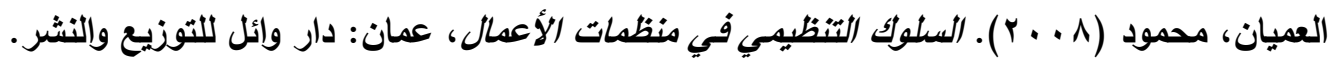


درجة ممارسة القيادة التشاركية وعلاقتها بالمناخ المنظمي في الأقسام الأكاديمية بالجامعات السعودية.

القيسي، هناء محمود ( • · ب). مبادئ الإدرة التريوية-نظريات- اتجاهات حديثة، عمان: دار

المناهج للنشر

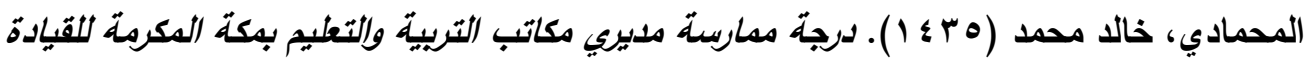

التشاركية وعلاقتها بالروح المغنوية من وجهة نظر المشرفين، رسالة ماجستير (غير

منشورة)، كلية التربية، جامعة أم القرى.

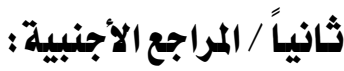

Adenik, A (2011). Organizational Climate as A Predictor of Employee Job Satisfaction from Covenant University. Business Intelligence Journal,4(1), P.P.151-165.

Huang, X.; Joyce, I. \& Yaping, G.(2010). Does Participative Leadership Enhance Work Performance by Inducing Empowerment Trust? The Differential Effects on Managerial and Non-Managerial Subordinates, Journal of Organizational Behavior, J. Organiz. Behav. 31, P.P. 122-143.

Kocolowski, M. (2010). Shared Leadership: Is It Time For a Change?, Emerging Leadership Journeys,3 (1),P.P. 22-32.

Muindi, M.(2011). The Relationship Between Participation In Decision Making and Job Satisfaction Among Academic Staff In the School of Business, University of Nairobi , Journal of Human Resources Management Research, 34, P.P. 246-460.

Sara, J. \& Chatziioannidis, G. (2013). Teacher participation in decision making and its impact on school and teachers. International Journal of Educational Management, 27 (2),P.P. 170-183.

Wippy, H, J. D. (2001). Leadership and Faculty Job Satisfaction at the University of Guam, Doctoral dissertation the university of Nebraska - Lincoln. 